Sex, hormones, and neurogenesis in the hippocampus: Hormonal modulation of neurogenesis and potential functional implications

Liisa A.M. Galea, Steven R Wainwright ${ }^{1}$, Meighen M. Roes ${ }^{1}$, Paula Duarte-Guterman ${ }^{1}$, Carmen Chow $^{1}$, Dwayne K. Hamson ${ }^{1}$

Centre for Brain Health, Program in Neuroscience, Department of Psychology, The University of British Columbia, Vancouver, BC, CANADA

${ }^{1}$ All co-authors contributed equally.

Send correspondence to:

Liisa Galea, Ph.D.

Professor

Distinguished University Scholar

Department of Psychology

University of British Columbia

2136 West Mall

Vancouver, BC

V6T1Z4

phone: 604-822-6536

FAX: 604-822-6923

webpage: www.psych.ubc.ca/ lgalea 


\begin{abstract}
The hippocampus is an area of the brain that undergoes dramatic plasticity in response to experience and hormone exposure. The hippocampus retains the ability to produce new neurons in most mammalian species and is a structure that is targeted in a number of neurodegenerative and neuropsychiatric diseases, many of which are influenced by both sex and sex hormone exposure. Intriguingly, gonadal and adrenal hormones affect the structure and function of the hippocampus differently in males and females. Sex differences in the effects of steroid hormones to modulate hippocampal plasticity should not be completely surprising as the physiology of males and females is different, with the most notable difference that the females gestate and nurse the offspring. Furthermore, reproductive experience (pregnancy and mothering) results in permanent changes to the maternal brain, including the hippocampus in females. Adult neurogenesis in the hippocampus is regulated by both gonadal and adrenal hormones in a sex and experience-dependent way. This review outlines the ability of gonadal and stress hormones to modulate multiple aspects of neurogenesis (cell proliferation and cell survival) in both male and female rodents. The function of adult neurogenesis in the hippocampus is linked to spatial memory and depression and this review provides early evidence of the functional links between hormonal modulation of neurogenesis to regulate cognition and stress.
\end{abstract}


Adolescence, pregnancy, postpartum and menopause are associated with dramatic changes in steroid hormone levels (Tulchinsky et al., 1972; Rannevik et al., 1995; Brett and Baxendale, 2001).and in turn a greater prevalence of neuropsychiatric disorders (Gutierrez-Lobos et al., 2002; Dekker et al., 2007; Barron and Pike, 2012). For the past two decades we have been researching how steroid hormones affect both brain and behaviour with an emphasis on hippocampal plasticity, cognition and depression. Sex differences are prevalent in steroid hormone-induced modulation of hippocampus-dependent neuroplasticity and cognition. These sex differences may be related to the sex-related differences in incidence and symptoms of neuropsychiatric and neurodegenerative disorders. For example, women are more likely to be diagnosed with depression (Gutierrez-Lobos et al., 2002) or Alzheimer's disease (Barron and Pike, 2012; Vest and Pike, 2013), while men or boys are more likely to be diagnosed with Parkinson's disease or autism (Miller and Cronin-Golomb, 2010; Pfaff et al., 2011). It is important to consider that females have a unique physiology allowing for gestation, parturition and lactation. This unique physiology may render females more vulnerable or resilient to certain neurological disorders. Indeed, pregnancy and motherhood are associated with a host of changes to brain, behaviour and endocrine profile (Workman et al., 2012) so it is not surprising that there may be permanent changes in the female brain's response to hormones. We have focussed on changes in the hippocampus, due to the involvement of this region in brain disorders modulated by sex and sex hormones and the fact that the hippocampus has a large concentration of steroid hormone receptors. This review will examine sex differences in hippocampal neurogenesis and how sex steroid hormones modulate neurogenesis in the hippocampus. Since its re-discovery in the early 1990s neurogenesis in the hippocampus has been linked to hippocampus-dependent cognition, stress and depression. Here we examine how these changes in neurogenesis with sex steroids may be related to both sex and hormone differences in hippocampus-dependent spatial ability and stress-induced depressive phenotype.

\section{Adult Hippocampal Neurogenesis}

Multipotent cells, often referred to as neural stem cells, are capable of unlimited selfrenewal, divide with a relatively low frequency, and produce numerous cell types (Reynolds and Weiss, 1992; Gage et al., 1995; McKay, 1997). However, dividing cells in the adult brain are primarily neural progenitor cells, dividing more frequently, but a limited number of times, and in a limited fashion, as they may only produce daughter cells of a defined glial or neuronal lineage (Gage, 2000; van der Kooy and Weiss, 2000; Seaberg and van der Kooy, 2003). Neural stem cells, were first identified in the adult brain of rodents more than 50 years ago (Altman, 1962), and have since been found across a variety of species including humans (Eriksson et al., 1998). Interestingly, the production of new neurons largely occurs in two regions: the subventricular zone, which lines the lateral ventricles, and the daughter cells migrating into the olfactory bulb via the rostral migratory stream, and the subgranular zone of the dentate gyrus in the hippocampus (Kaplan and Hinds, 1977). Intriguingly, while the existence of neurogenesis in adult humans has been verified numerous times in the dentate gyrus (Spalding et al., 2013), there is less conclusive evidence that it exists in the subventricular zone of humans (Sanai et al., 2011). 
The production of new neurons may be identified though the labelling of DNA as it is synthesized during mitosis using exogenous markers such as the radiolabelled nucleotide ${ }^{3} \mathrm{H}$ thymidine or a synthetic thymidine analogue such as 5-bromo-2-deoxyuridine (BrdU). Administration of BrdU (or other synthetic thymidine analogues) results in their incorporation in to the DNA of every cell undergoing DNA synthesis during the two hours after injection, and may be used to examine labelled cells at time points ranging from hours, weeks or even years later depending on the timeline of interest (Eriksson et al., 1998; Dayer et al., 2003; Kempermann et al., 2003). However, these markers are limited in that they become diluted as cells continue to divide and are only distinguishable from background for 4-5 divisions following administration (Stone et al., 1965; Prickaerts et al., 2004). Moreover, exogenous markers of DNA synthesis are affected by a number of factors that may disrupt detection of true cell counts such as toxicity/dose or blood-brain barrier permeability (Taupin, 2007). Exogenous DNA synthesis markers are limited, in that they must be used in conjunction with endogenous markers (such as neuronal nuclei; NeuN) to identify labelled cells as neurons. Thus merely identifying cells as having been produced in the adult brain, without further demonstrating that they survive and become neurons, is insufficient to demonstrate that neurogenesis has occurred. Endogenous markers do exist for both cell proliferation (e.g. Ki67) and immature neurons (e.g. doublecortin; DCX). The use of endogenous markers such as DCX and NeuN facilitate the identification and characterization of new neurons in the adult brain without the same caveats as the use of exogenous DNA synthesis markers (Taupin, 2007). However, endogenous markers also have their limitations (see review by von Bohlen und Halbach (2011)).

It is important to note that neurogenesis, as defined here, requires the proliferation, migration, survival, and differentiation of newly generated cells into neurons. Any number of internal and/or external factors may independently affect the proliferation of progenitor cells, their differentiation into neurons, migration, or their survival rates, including hormones (Kempermann et al., 1998a; van Praag et al., 1999; Malberg et al., 2000; Barker and Galea, 2008; Burgess et al., 2008; Pariante and Lightman, 2008; Anacker et al., 2011; Surget et al., 2011; Wainwright et al., 2011). Thus it is important to understand when and what aspects of neurogenesis are being examined in relation to hormonal manipulation as different times of BrdU administration can significantly affect the outcome (see below and Figure 1).

Although new neurons can be labelled and observed, the exact role of these neurons in the function of the hippocampus remains to be fully elucidated. There is solid evidence that new hippocampal neurons are involved in some forms of hippocampus-dependent learning and memory (Shors et al., 2001; Snyder et al., 2005a; Clelland et al., 2009; Epp et al., 2013) and perhaps more ambiguously, these new neurons have been associated with the etiology and treatment of depression (Santarelli et al., 2003; Boldrini et al., 2009; Boldrini et al., 2012). Interestingly, the hippocampus seems to be functionally dissociated along the dorsal-ventral axis, wherein the dorsal region plays a larger role in cognitive faculties, while the ventral region is more involved in emotionality (Bannerman et al., 2004; Fanselow and Dong, 2010). Studies are just beginning to untangle the effects of different hormones on neurogenesis in the dorsal or 
ventral hippocampus (Brummelte and Galea, 2010; Chow et al., 2013). It is important to keep in mind when reviewing the literature that there are numerous differences in hippocampal neurogenesis that exist between rats and mice and likely other species; specifically newly generated neurons maturate, survive, and incorporate into functional circuits at higher rate in rats than mice (Snyder et al., 2009). Importantly, gonadal and adrenal hormones modulate both hippocampal neurogenesis and hippocampal function such as cognition and depressive-like endophenotypes in rodents and humans (McEwen, 2001; Barha and Galea, 2010b). This review

will focus on the hormonal modulation of adult hippocampal neurogenesis as well as the possible functional implications of these modulations in hippocampus-linked cognition and depression.

\section{Sex differences in Neurogenesis in the Hippocampus}

More than a decade ago the first reports of sex differences in hippocampal neurogenesis in adult rats and voles were published. In both meadow voles and Sprague-Dawley (SD) rats, females have higher levels of cell proliferation (depending on the reproductive status) compared to males, in the dentate gyrus of the hippocampus (Galea and McEwen, 1999; Tanapat et al., 1999). These sex differences are dependent on natural fluctuations of gonadal hormones (seasonal or estrous cycle). During proestrus, when estradiol levels are highest, cell proliferation is highest compared to female rats in estrus or diestrus (Tanapat et al., 1999). In laboratory and wild female meadow voles, cell proliferation varies during the reproductive season, with the lowest levels during the breeding season and the highest levels of during the non-breeding season (Galea and McEwen, 1999; Ormerod and Galea, 2001). The discrepancies between these studies had to do with timing of estradiol exposure and DNA synthesis marker injection (Ormerod and Galea, 2001 and see below). Nevertheless, sex differences in cell proliferation are not seen across all mammalian species. For example, no sex differences in cell proliferation are observed in squirrels (Lavenex et al., 2000) or in laboratory mice (C57BL/6J strain: (Lagace et al., 2007; Ben Abdallah et al., 2010a; Klaus et al., 2012) B6SJL strain: (Ma et al., 2012)). It is important to note though that sex differences in cell proliferation, favouring females, are only observed under certain reproductive status conditions in meadow voles and SD rats (Galea and McEwen, 1999; Tanapat et al., 1999; Ormerod and Galea, 2001) and it is not always clear what the reproductive status of the females tested were in prior studies in squirrels and mice. Nonetheless, various studies have found evidence that fluctuations in gonadal hormones modulate hippocampal neurogenesis in mice and rats and subsequent studies have examined the role and mechanisms of androgens, estrogens and progesterone on neurogenesis in the hippocampus of adult male and female rodents and are reviewed below.

\section{Aging, Reproductive Experience and Neurogenesis}

Pregnancy and early motherhood are accompanied by vast endocrine changes in steroid and peptide hormones, such as oxytocin, estradiol and progesterone, that stimulate maternal behavior (Rosenblatt, 1988), alter cognitive performance (Workman et al., 2012) and induce changes in neural circuitry (Fleming et al., 1999) in rodents. The neural and behavioral changes 
occurring during pregnancy and lactation reveal a large degree of plasticity in the maternal brain that result from both endocrine changes and exposure to offspring (Pawluski et al., 2009; Macbeth and Luine, 2010). In humans, brain size decreases across pregnancy and returns to preconception size after delivery (Oatridge et al., 2002). The hippocampus, though not typically considered to be part of the maternal circuit, underlies a number of maternal behaviors including pup retrieval and nest building, it is also one brain area particularly sensitive to pregnancy and parturition-related hormones (Pawluski et al., 2009).

Pregnancy and/or motherhood are associated with changes in the structure and function of the hippocampus. Spine density in the CA1 region increases during pregnancy and lactation compared to nulliparity in SD rats (Kinsley et al., 2006). These changes in hippocampal morphology are likely due to pregnancy-related endocrine changes, as nulliparous females treated with hormonal-simulated pregnancy undergo similar changes in spine density of hippocampal CA1 pyramidal cells (Kinsley et al., 2006). After weaning, primiparous females show significant dendritic remodelling of CA1 and CA3 pyramidal cells, with decreased dendritic length and branch points compared to nulliparous female SD rats (Pawluski and Galea, 2005). While, multiparous rats show greater spine density in the basal region of CA1 pyramidal neurons compared to nulliparous rats (Pawluski and Galea, 2005). These findings indicate not only that pregnancy and the postpartum period are times of maximal plasticity but also that this plasticity is highly dependent on time and reproductive experience. The alterations in hippocampal pyramidal cell morphology resulting from pregnancy and motherhood are accompanied by time- and parity-specific changes in hippocampal neurogenesis and cognition (for a review, see Workman et al., 2012; Macbeth \& Luine, 2010). The immediate postpartum period is associated with a transient decrease in cell proliferation in both primiparous and multiparous female SD rats. In contrast, the survival of new neurons during the postpartum period differs among parous groups: Whereas multiparous SD females do not differ from nulliparous females in cell survival across the first two (Darnaudery et al., 2007) or three (Pawluski and Galea, 2007) weeks after parturition, primiparous SD females show decreased cell survival across the postpartum period, and this difference is attributable to pregnancy alone (Pawluski and Galea, 2007). Intriguingly, mothering experience alone (23 days of pup exposure in nulliparous rats) increases neurogenesis in the hippocampus, whereas pregnancy and mothering (in primiparous females) decreases neurogenesis in the same time frame (Pawluski and Galea, 2007). In addition to affecting cell proliferation and survival, pregnancy and mothering alter the electrophysiological properties of the hippocampus as long-term potentiation (LTP) is augmented along Schaffer collaterals in multiparous C57BL6 mice who have mothered for 3 days (Tomizawa et al., 2003).

Concurrent with the functional and plastic changes of the hippocampus with parity are alterations in learning and memory. In both animal and human studies, memory impairments of the third trimester and early postpartum period are transient and may even give way to enhanced cognition within a year of parturition. In humans, verbal memory and word recall are negatively affected by pregnancy and parturition (see Macbeth \& Luine, 2010 for review) and are 
significantly reduced immediately postpartum (Eidelman et al., 1993; Glynn, 2010). However, verbal memory and attention skills in postpartum women are equivalent to those of non-mothers 10-13 months after delivery (Crawley et al., 2003) and may even be enhanced by 2 years postpartum (Buckwalter et al., 2001). It is important to note that some cognitive impairments during gestation and the early postpartum are dependent on fetal sex (Vanston and Watson, 2005) and parity (Glynn, 2012). In SD and Long-Evans (LE) rats, reproductive experience (pregnancy and motherhood) is associated with enhanced memory on a variety of hippocampus-dependent tasks including the radial arm maze (Kinsley et al., 1999; Pawluski et al., 2006b; Pawluski et al., 2006a), object placement (Paris and Frye, 2008), social learning (Fleming et al., 1994) and water maze tasks (Kinsley et al., 1999) in the weeks following weaning. In summary, pregnancy and mothering have time- and parity-dependent changes in cognition and hippocampal neurogenesis, morphology, and electrophysiology.

Differences in hippocampal morphology and neurogenesis among multiparous, biparous, primiparous, and nulliparous females point to possible lingering effects of reproductive experience on cognition and hippocampal function, long after parturition. Consistent with the existence of enduring effects of reproductive experience, a number of behavioral studies indicate persisting effects of parity and exposure to offspring on cognition and brain health. Primiparous and multiparous SD rats show enhanced learning and memory compared to nulliparous rats long after last exposure to pups when repeatedly tested in the dry land maze (Gatewood et al., 2005; Love et al., 2005), water maze (Lemaire et al., 2006), reversal learning tasks (Gatewood et al., 2005), and object recognition and object placement tasks (Macbeth et al., 2008) in middle age. Multiparity continues to be associated with enhanced spatial learning and memory well into reproductive senescence ( 2 years of age) when repeatedly tested across the lifespan (Gatewood et al., 2005; Lemaire et al., 2006). The enhancement in LTP associated with parity in young mice (Tomizawa et al., 2003) persists in 22-month old primiparous Wister rats (16 months after parturition) show the same enhancement of excitatory post-synaptic potentiation (Lemaire et al., 2006). Finally, reproductive experience is associated with enduring changes in maternal behavioral responsiveness (Bridges, 1975; Scanlan et al., 2006). These persisting effects are likely mediated by changes in brain and perhaps hippocampal circuitry. Three months after weaning, multiparity is associated with increased BDNF (Macbeth et al., 2008) and decreased amyloid precursor protein (Gatewood et al., 2005) compared to nulliparous rats. Both amyloid precursor protein and BDNF levels are regulated by estradiol (Jaffe et al., 1994; Scharfman and MacLusky, 2006) and are thought to play roles in learning and memory during aging (Turner et al., 2003; Tapia-Arancibia et al., 2008). In addition, dopamine sensitivity is increased in parous rats compared to nulliparous SD rats (Byrnes et al., 2001), and dopamine sensitivity seems to underlie the enhanced maternal responsiveness and memory for maternal behavior seen in parous SD females (Byrnes et al., 2002). These persisting effects may be due to parity-induced changes in secreted levels of estradiol (Bridges and Byrnes, 2006) along with changes in sensitivity to estradiol, as parous rats are more sensitive to high doses of estradiol (Bridges and Byrnes, 2006) and estradiol in turn regulates dopamine sensitivity (See Byrnes et al., 2001 for a discussion). 
Therefore, a variety of neural and endocrine processes are altered by reproductive experience long after weaning, influencing cognition and behavior as a mother ages.

Aging is a multifaceted process that involves dramatic changes in the endocrinology of the brain (Bishop et al., 2010) and circuitry of the hippocampus. Aging is characterized by an increase in circulating levels of glucocorticoids (Cameron and McKay, 1999) and decreased steroid responsivity in the brain (Sapolsky et al., 1984; Wilkinson et al., 1997). Gonadal hormones, in contrast, decrease with aging in both women and men (Lamberts et al., 1997). The high levels of corticosteroids and diminishing levels of ovarian hormones as women age may be at least partially responsible for age-related declines in cognition. Adrenalectomized animals do not show typical decline in neurogenesis with age (Gould et al., 1992), and estradiol application attenuates age-related cognitive decline in a number of species (see above and (Gibbs and Gabor, 2003), possibly due to their regulation of adult hippocampal neurogenesis (reviewed in other sections). Estrogens have been investigated as possible agents for improving cognitive aging in postmenopausal and surgically menopausal women with some evidence of efficacy (see Sherwin, 2006 for a review). Factors, such as previous reproductive experience, that change estrogen levels or sensitivity to estrogens may therefore have potent effects on both cognition and brain health.

A further age-related change in the female brain is an apparent alteration in the hippocampus' response to estrogens. Treatment with $17 \beta$-estradiol does not affect granule cell dendritic spine density in young (3 months old) female rats but does increase spine density in middle-aged (14 months old) female SD rats back to levels seen in their young counterparts (Miranda et al., 1999). It is worth noting that in that particular study, older female rats had been behaviourally tested twice (once at 3 months and another time at 14 months) which may have influenced the results. Furthermore, $17 \beta$-estradiol replacement restores ovariectomy-induced impairment in reference memory in younger rats, enhances performance in middle-aged females, but does not influence performance in aged females (Talboom et al., 2008). In this study, the cognitive effects of ovariectomy differed across age groups, with surgical ovarian hormone loss impairing cognition in young adult female rats and enhancing cognition in old age. Therefore it seems that age alters both the responsiveness of the hippocampus to estrogens and the impact of estrogens on cognition.

Altered hippocampal function, and reduced hippocampal neurogenesis, likely contribute to age-related declines. Hippocampus-dependent tasks are sensitive to age-related cognitive decline (Foster, 1999), and exercise-induced increases in hippocampal neurogenesis improve performance on spatial learning tasks in aged rodents (van Praag et al., 2005). Aging is associated both with cognitive decline and an exponential decline in hippocampal neurogenesis (Epp et al., 2009; Lazarov et al., 2010), raising the possibility that age-related cognitive deficits may result from a suppression of neurogenesis. Although hippocampal neurogenesis declines with age (Seki and Arai, 1995; Kuhn et al., 1996; Bizon and Gallagher, 2003; Ben Abdallah et al., 2010b), the neurons that are added to the dentate gyrus later in life appear to display functional and morphological features equivalent to those of adult-generated neurons produced 
in early adulthood (Morgenstern et al., 2008; Toni et al., 2008). The mechanism of neurogenesis suppression remains unclear. Age does not affect the maturation or migration of newborn cells (McDonald and Wojtowicz, 2005; Rao et al., 2005). Findings regarding the effects of age on differentiation of newborn cells are mixed. Rao et al (2005) found no effect of age on phenotype (glial or neuronal) of newborn cells, whereas Lichtenwalner et al. (2001) found a 60\% reduction of differentiation into neurons in senescent rats and Mcdonald and Wojtowicz (2005) report a $20 \%$ reduction in differentiation in middle-aged rats. The raw number of surviving new cells decreases with aging (Kempermann et al., 1998b; van Praag et al., 2005). However, when reductions in proliferation are accounted for, the proportion newborn cells surviving to maturity does not differ as a function of age (Bondolfi et al., 2004). Instead, reductions in neurogenesis with age seem to be overwhelmingly driven by the vast reductions in proliferation of neural progenitor cells that reliably occur with aging (Kempermann et al., 1998b; Bondolfi et al., 2004; McDonald and Wojtowicz, 2005; Rao et al., 2005). Moreover, in rodents the reduction in neurogenesis with age does not seem to result from a depletion of the neural stem cell population (Hattiangady and Shetty, 2008). Nor does reduced neurogenesis result from increased length of the cell cycle (Olariu et al., 2007). These findings suggest that, rather than becoming aberrant, neurogenesis in the aged brain is simply downregulated and is a result of increased quiescence of the neural stem cell population.

The studies just described imply that factors that increase proliferation of the neural precursor cell population could greatly influence the maintenance of brain health, plasticity, and cognition with aging. As reviewed in subsequent sections of this review, estrogens greatly impact hippocampal function and neurogenesis across the lifespan. Thus factors that increase estrogen levels and estrogen sensitivity may therefore have potential for alleviating age-associated cognitive decline in women. Reproductive experience may represent one such moderator. Reproductive experience is associated with delayed reproductive senescence and delayed cessation of estrous cycling in rats (Matt et al., 1987). In women, parity is associated with later onset of menopause (Gold et al., 2001). Maternal brains may therefore be exposed to more estrogens over the lifespan. Moreover, reproductive experience changes the way the brain responds to estrogens in later life (Barha and Galea, 2011). Estradiol is the most potent of the estrogens and is present at the highest concentration levels in premenopausal women, while estrone and estriol are the less potent estrogens (Rannevik et al., 1995). Estriol is present at high levels during pregnancy, while estrone is the main estrogen in postmenopausal women (Tulchinsky et al., 1972; Brett and Baxendale, 2001). While both estrone and estradiol levels decrease in women after menopause a shift in the ratio of estrone to estradiol exists such that after menopause estrone is present at higher levels than estradiol. Cell proliferation in the hippocampus is upregulated in response to estrogens (17 $\beta$-estradiol, $17 \alpha$-estradiol, and estrone) in middle-aged multiparous, but not nulliparous, female rats (Barha and Galea, 2011), indicating that parity may enhance sensitivity to estrogens in later life. Though one must be careful not to assume enhanced neurogenesis necessitates improved cognition, persisting changes in how the brain responds to estrogens with reproductive experience may have profound implication for 
healthy cognitive aging. Further research is required to elucidate the neural mechanisms by which reproductive experience improves cognition in late life in female rats. In particular, investigations of effects of reproductive experience on neurogenesis and other forms of plasticity in aging gonadally-intact rats are lacking.

One open question concerning the possible role of neurogenesis in cognitive aging is whether new neurons behave the same in old animals as they do in young animals. Whereas neurogenesis levels generally correlate with performance on hippocampus-dependent tasks in young animals and ablating neurogenesis impairs learning in a number of hippocampaldependent tasks in young animals (see Deng et al., 2010 for a review), correlations between neurogenesis and cognition have been variable in aged animals. Several studies find positive correlations between new neuron number and cognitive measures in aged rodents (Lemaire et al., 2000; Drapeau et al., 2003; Driscoll et al., 2006) and nonhuman primates (Aizawa et al., 2009), whereas others have found no effect of ablating neurogenesis (Martinez-Canabal et al., 2013) and no or negative associations of neurogenesis with cognition in aged animals (Bizon and Gallagher, 2003; Merrill et al., 2003; Bizon et al., 2004). Conflicting findings may be due to task demands such as distributed versus massed learning and the speed of learning required by the task (Speisman et al., 2013); however, they also raise the question of the functional importance of neurogenesis in aged animals and as a mechanism of parity-related cognitive changes with aging. Furthermore as reviewed below it may not simply be the number of new neurons created but how those new neurons are activated in response to appropriate stimuli and studies have yet to be conducted exploring immediate early gene (IEG) activation in new neurons in older animals.

\section{Stress, Depression and Neurogenesis:}

The hippocampus shows a great degree of plasticity when exposed to gonadal hormones (see sections below), an effect also evident with exposure to stress hormones. The hippocampus regulates the hypothalamic-pituitary-adrenal (HPA) axis through a negative feedback mechanism via mineralocorticoid (MR) and glucocorticoid receptors (GR), both of which are highly expressed in the dentate gyrus (McEwen et al., 1986; De Kloet and Reul, 1987; De Kloet et al., 1998). Interestingly newly generated neurons in the dentate gyrus may be particularly important in the HPA negative feedback mechanism (Snyder et al., 2011).

The hippocampus is vulnerable to the effects of stress. For instance, exposure to chronic stress reduces adult hippocampal neurogenesis, decreases expression of synaptic proteins, causes retraction of dendritic branches and reduces spine density in CA3 and CA1 regions of the hippocampus (McEwen, 1999). Indeed, chronic stress is associated with hippocampal atrophy and is cited as the primary preceding factor in the etiology of depression (Sapolsky, 1986; Sapolsky et al., 1988; Schule, 2007). Depressed patients show abnormal HPA function such as abnormal diurnal secretion of cortisol resulting in a flattened circadian rhythmic activity, and the hypersecretion of cortisol (Parker et al., 2003; Schule, 2007). In fact, dysregulation of the HPA system is the most prominent endocrine change seen with depression, and is thought to play an 
important role in the pathophysiology of depression (Holsboer, 2000, 2001). Given the profound dsyregulation of HPA negative feedback in depression, normalizing the HPA axis is one of the major targets of recent therapies (Keck, 2006; Schule, 2007). Depressed patients show reduced hippocampal volume which may be due to reduced dendritic complexity, decreased neuron soma size, and reduced hippocampal neurogenesis (Stockmeier et al., 2004; Boldrini et al., 2009; Hercher et al., 2009). Importantly, the reduction in hippocampal volume co-varies with in the number of depressive episodes and the duration of the illness (Sheline et al., 1996; Sheline et al., 2003; McKinnon et al., 2009). Interestingly, sex differences are evident in the hippocampal volumes of depressed patients, with men presenting with a profound reduction of hippocampal volume compared to women (Frodl et al., 2002). Animal models of depression typically capitalize on the association between stress and depression; in rodents exposure to chronic unpredictable stress shows good etiological face validity, as the alterations to the hippocampus are similar to those seen in depressed patients, as well as good construct, and predictive validity for antidepressant efficacy (Vollmayr et al., 2007). Chronic stress exposure reduces dendrite length and complexity (Watanabe et al., 1992; Galea et al., 1997), spine density (Magarinos and McEwen, 1995), the expression of proteins associated with synaptic plasticity (Bessa et al., 2009; Muller et al., 2011), and adult neurogenesis in the hippocampus (Czeh et al., 2002; Alonso et al., 2004; Bessa et al., 2009). However there is a major caveat, as sex differences exist in the influence of stress on neural plasticity. For instance, chronic restraint stress produces atrophy of the apical CA3 dendrites of males but only in the basal CA3 dendrites of females (Galea et al., 1997). Importantly, the effects of stress on hippocampal neurogenesis are also altered by sex, as males show reduced cell proliferation and survival while females actually show enhanced cell proliferation in response to chronic foot shock stress (Westenbroek et al., 2004). It is important to acknowledge these differences and investigate the influence of sex in mediating the pathoetiology and treatment of depression.

\section{Antidepressant effects on HPA and Neurogenesis:}

Given the clinical evidence of reduced hippocampal volume in chronically depressed patients and the implication of decreased hippocampal neurogenesis, efficacious antidepressant treatment should therefore reverse these putatively pathological states. There are a number of different classes of antidepressants: selective serotonin reuptake inhibitors (SSRI), tricyclic antidepressants (TCAs), monoamine oxidase inhibitors (MAOI) and selective norepinephrine reuptake inhibitors (SNRI). Unless otherwise stated multiple antidepressants have been used in studies particularly involving patients. Indeed chronic antidepressant treatment enhances hippocampal volume in both depressed patients (Sheline et al., 2003; Videbech and Ravnkilde, 2004; Malykhin et al., 2010) and in animal models of depression (Willner, 2005; Bessa et al., 2009). Moreover, chronic, but not acute antidepressant (SSRI or TCA) treatment enhances hippocampal neurogenesis, via an upregulation of cell proliferation, in a manner that is temporally coincident with behavioural efficacy (Malberg et al., 2000). These findings have led to the development of a neurogenic hypothesis of depression, wherein it is proposed that 
reductions in hippocampal neurogenesis may underlie the pathoetiology of depression, while conversely the efficacy of antidepressant treatment is dependent upon an upregulation of hippocampal neurogenesis (Jacobs et al., 2000). Indeed post-mortem studies have shown that antidepressant treatment increases hippocampal neurogenesis via cell proliferation (greater effect with TCAs) and increased immature neurons (Boldrini et al., 2009; Boldrini et al., 2012). Additionally, we recently found sex and age effects of antidepressant treatment on the expression of DCX or p21, a cell cycle arrest marker, in the hippocampus of depressed patients (Epp et al., in press), further illustrating the need to examine sex as an independent factor in neurogenesis research. The negative feedback regulation of the HPA axis is also amended with chronic antidepressant treatment (Schule, 2007) which suggests that the functionality of the hippocampus is improved with antidepressant treatment. Studies show that antidepressant treatment enhances both the expression and function of GRs and MRs, an effect which likely mediates the normalisation of HPA function via improved negative feedback regulation on the PVN (Pariante et al., 2004). Stabilization of negative feedback inhibition of the HPA axis by antidepressants has been related to improved mood scores, an effect that may precede or be coincident with the alleviation of depressive symptoms in humans (Ising et al., 2007). However, it must be noted that this is not always the case, as studies have shown antidepressant treatment to be efficacious despite maintained dysregulation of the HPA axis (Zobel et al., 1999; Zobel et al., 2001), while others have shown inefficacy of antidepressant treatment despite a return in to normal HPA function (Schule et al., 2001; Schule et al., 2003; Schule et al., 2006). Interestingly, sex has also been implicated in the antidepressant-mediated regulation of HPA function, where males responding to treatment show better normalization of HPA negative feedback following antidepressant treatment than observed in females (Binder et al., 2009).

A dynamic relationship may exist between stress and neurogenesis, wherein a direct interplay between the two may underlie antidepressant efficacy. A recent study by Snyder and colleagues (2011) showed that the ablation of neurogenesis hinders the re-establishment of basal HPA tone following stress and induced a depressive-like phenotype in both the FST and sucrose preference test. Other studies have suggested that the ability of antidepressants to ameliorate HPA dysregulation is an integral mechanism through which antidepressants exert their effects (Pariante and Lightman, 2008). A recent study has shown that the HPA dampening effects of chronic SSRI treatment are neurogenesis-dependent (Surget et al., 2011). Interestingly, the ablation of neurogenesis alone did not alter HPA activity; rather only the ability of antidepressant treatment to restore normalized HPA function following chronic stress requires the contribution of hippocampal neurogenesis. It therefore appears that reductions in neurogenesis may underlie the pathology of depression and the ability of antidepressant drugs to upregulate neurogenesis may be essential to efficacy. Both the pathology and successful treatment of depression may be tied to HPA activity and adult neurogenesis in the hippocampus. However, the mechanism through which antidepressants enhance neurogenesis is a matter of debate. Intriguingly, a recent in vitro study of human hippocampal progenitor cells suggests a GR-dependent mechanism (Anacker et al., 2011). The application of a GR-antagonist prevents the antidepressant-mediated 
increase in the differentiation of neuroblasts to a neural phenotype, while increases in proliferation only occurred when the antidepressant was co-administered with dexamethasone, a GR agonist. Previous in vivo studies have also shown that antidepressant-mediated (SSRI) increases in neurogenesis require the presence of glucocorticoids (David et al., 2009) or rhythmic change in glucocorticoid levels (Huang and Herbert, 2006). It therefore appears that a delicate balance may exist in the reciprocal relationship between the activation of GRs, a subsequent upregulation of neurogenesis, and the requirement of neurogenesis for the appropriate regulation of the HPA axis. If this balance is disrupted, the subsequent reductions in neurogenesis due to an over-expression of corticosteroids could lead to the loss of feedback inhibition and a flattened, hyper-responsive HPA axis, resulting in a destructive positive feedback loop which may ultimately result in depression. Certainly caveats to this model do exist, as the majority of ablation studies do not observe the development of a depressive phenotype (Santarelli et al., 2003; Surget et al., 2008; Bessa et al., 2009; David et al., 2009; Surget et al., 2011), including no reductions in hippocampal volume, alterations in HPA reactivity, or increases in depressive-like behaviours. Moreover, the contribution of neurogenesis to antidepressant (fluoxetine) efficacy typically appears only in certainly behavioural measures of preclinical models (David et al., 2009; David et al., 2010). Further research is certainly necessary to fully elucidate the role of neurogenesis in both HPA regulation and antidepressant efficacy, particularly in comparison to broader alterations in neural plasticity (Wainwright and Galea, 2013).

\section{Sex, Hormones, and Depression:}

A marked sex difference exists in the prevalence of depression, as women are twice as likely as men to develop depression (Gutierrez-Lobos et al., 2002). Several psychosocial theories regarding this sex difference do exist, however the prevailing neurobiological hypothesis suggests that gonadal hormones may play a role in the pathoetiology of depression (Hammarstrom et al., 2009). Interestingly, a close interaction exists between the HPA axis and the hypothalamic-pituitary gonadal (HPG) axis where glucocorticoids function to directly inhibit the production gonadal hormones in a sex-dependent manner (Viau, 2002). Testosterone and estradiol directly interact with the HPA axis in a complex, sex-dependent manner. Females have higher glucocorticoid levels than males under both basal and stress conditions (Kitay, 1961; Le Mevel et al., 1979). This difference in HPA output is indicative of the opposing effects of gonadal hormones in males and females. The removal of testicular hormones through castration increases HPA activity in males, while testosterone replacement reverses this effect, acting to reduce corticosteroid levels (Handa et al., 1994b; Viau and Meaney, 1996; Viau, 2002). Conversely, ovariectomy results in decreased HPA activity, while estradiol replacement reverses this effect through the enhancement of corticosteroid output in females (Burgess and Handa, 1992). Furthermore, increased corticosterone levels are seen in female rats during proestrus (Viau and Meaney, 1991). These findings suggest a causal relationship between gonadal hormones and HPA output albeit in different directions in males and females. Given the apparent 
roles of testosterone and estradiol in reducing and enhancing glucocorticoid release, respectively, both hormones have been implicated in depression and antidepressant treatment.

There is an increased incidence of depression in males coinciding with the age-related decline in testosterone levels (Shores et al., 2004; Shores et al., 2005; McIntyre et al., 2006; Shores et al., 2009). Similarly, young hypogonadal males are more susceptible to developing depression (Veras and Nardi, 2010), which supports the notion that testosterone confers resiliency against the development of depression. Moreover, testosterone replacement therapies have shown some antidepressant efficacy in hypogonadal men (Seidman and Rabkin, 1998; Shores et al., 2009; Zarrouf et al., 2009); however replacement therapies are not always effective, and there is some indication that age may be a factor, with young males typically showing better response rates (Seidman et al., 2001; Pope et al., 2010; Veras and Nardi, 2010). Testosterone replacement also has efficacy as an adjunct treatment to clinical antidepressants in cases of treatment-resistant depression (Seidman and Rabkin, 1998; Pope et al., 2003). Interestingly, sex differences are also seen in antidepressant efficacy as men are reported to have a better response to TCAs while women have a better response to SSRIs (Kornstein et al., 2000). Furthermore older postmenopausal women show better response to SSRIs on hormone replacement therapies compared to postmenopausal women not on HRT (Thase et al., 2005). Our recent findings that older depressed women taking antidepressants have greater expression of a cell cycle arrest marker, p21, compared to younger depressed women and men and older depressed men taking antidepressants is in line with the suggestion that gonadal hormones maybe a factor in antidepressant efficacy.

Gonadal hormones in females are also likely a factor in the treatment and etiology of depression. Times of hormonal fluctuation, such as postpartum and perimenopause, are associated with an increased incidence in depression (Hendrick et al., 1998; Cohen et al., 2006); as with hypogonadal men, hormonal replacement shows antidepressant effects, as a monotherapy or as an adjunct therapy with antidepressant drug treatment in both peri- and post-menopausal women (Soares et al., 2001; Rasgon et al., 2002; Soares et al., 2003). Mirroring the clinical findings, pre-clinical studies have shown that gonadal hormones, in both males and females, function in an antidepressant capacity. Moreover, these studies also give further credence to the suggested role of neurogenesis in the etiology and treatment of depression. Castrated male rats are more likely to develop a depressive-like phenotype than intact males when submitted to chronic stress, where intact males also show significantly greater levels of hippocampal neurogenesis and resiliency to stress effects on the hippocampus (Wainwright et al., 2011). Moreover, testosterone shows antidepressant efficacy alone (Buddenberg et al., 2009; Frye and Walf, 2009), and as an adjunct treatment to the antidepressant imipramine (Carrier and Kabbaj, 2012). Intriguingly, Carrier and Kabbaj (2012a) reported that imipramine, a tricyclic antidepressant, upregulated cell proliferation only when given to intact or castrated male rats given testosterone, suggesting that testicular hormones may regulate cell proliferation via other pathways. This is somewhat similar to the effects of imipramine to upregulate cell proliferation in intact versus ovariectomized female rats (Green and Galea, 2008). These findings collectively 
suggest that ovarian and testicular hormones are needed to show the normal imipramine-induced increase in cell proliferation. The influence of sex and hormone status on the etiology of a depressive-like phenotype and on antidepressant efficacy is also seen in rodents, as estradiol administration shows antidepressant efficacy in an estrogen receptor- $\beta$ dependent mechanism (Rocha et al., 2005). As with males, an interaction appears to exist between gonadal hormones and antidepressant efficacy in females. Chronic imipramine increases hippocampal neurogenesis in intact but not in ovariectomized rats (Green and Galea, 2008). Another study found that an SSRI decreased immobility in the FST but only in estradiol-treated ovariectomized female rats (Sell et al., 2008). Consequently androgens and estrogens may have antidepressant properties which could impede the development of, or ameliorate, extant depressive disorders.

\section{Estrogens, Learning, and Memory}

Hippocampal neurogenesis has been linked to spatial learning and memory (See Epp et al., (2013) and Winocur et al.,(2006) for review). Ovarian hormones not only modulate neurogenesis in the hippocampus but also modulate hippocampus-dependent learning and memory across a variety of species from rodents to primates (Barha and Galea, 2010b). Deprivation of endogenous ovarian hormones via ovariectomy can be associated with a decline in cognitive function in humans and rodents (Gibbs, 1999; Hogervorst et al., 2000; Gibbs and Johnson, 2008; Sherwin and Henry, 2008). Over the course of the menstrual cycle, performance on various cognitive tasks correlates with fluctuations in ovarian hormone levels (Hampson, 1990; Galea et al., 1995; Warren and Juraska, 1997; Dietrich et al., 2001) (for review see Workman et al., (2012)). For example, women in the menses phase (lower levels of ovarian hormones) perform better on spatial rotation tasks and show different brain activation patterns, as measured by fMRI compared to women in the midluteal phase (elevated ovarian hormone levels) (Hampson, 1990; Dietrich et al., 2001). Similarly, female rats and meadow voles with higher circulating estrogens show impairments in spatial learning (Galea et al., 1995; Warren and Juraska, 1997), a greater preference for allocentric navigation strategies (Korol et al., 2004; Rummel et al., 2010), and more effective spatial memory retrieval (Chow et al., 2013), compared to female rats with lower levels of circulating estrogen.

The widely criticized Women’s Health Initiative Memory Study (WHIMS) found that Premarin, a commonly prescribed hormone replacement, conferred no significant cognitive benefit to postmenopausal women (Rapp et al., 2003; Shumaker et al., 2003; Espeland et al., 2004). This study has been criticized over a number of design flaws, including the long period (greater than 10 years) since menopause before the use of HRT, the advanced age and disease state of the participants, and the composition of HRT given (Harman et al., 2004; Sherwin, 2005). There are a number of studies illustrating that longer times after ovarian hormone deprivation is related to poorer response (for review see: Frick, 2012). Meta-analyses shows that the conjugated equine estrogen, Premarin, which is comprised of $50 \%$ estrone sulphate and only $0.5 \%$ estradiol sulphate, is less effective than $17 \beta$-estradiol-based therapies in protecting against cognitive decline in postmenopausal women (Hogervorst et al., 2000; Ryan et al., 2008). Studies 
show that estradiol has a dose- and task-dependent effect spatial memory, with lower levels of estradiol enhancing spatial working memory and higher levels of estradiol impairing spatial reference memory in rats (Daniel et al., 1997; Galea et al., 2001; Holmes et al., 2002).

Furthermore, while both a low and moderate dose of $17 \beta$-estradiol could enhance spatial working memory, only rats treated with the moderate dose continued to show this enhancement as working memory load increased over the course of training (Bimonte and Denenberg, 1999). Davis and colleagues (2005) showed that chronic high dose of estradiol enhanced spatial reference memory in the radial arm maze, but required more trials to reach criterion in the nonspatial task compared to ovariectomized rats. Therefore, dose-dependent effects of estradiol can vary with the nature of the task. Furthermore different estrogen receptors are implicated in estrogens effects on learning and memory and the reader is directed to an excellent review on this subject (Frick, 2012).

The majority of studies on hippocampus-dependent cognition have examined the effects of estradiol and few studies have examined the effects of estrone. An acute low dose of $17 \beta$ estradiol or $17 \alpha$-estradiol, facilitated contextual fear conditioning, but higher doses impaired contextual fear conditioning in female SD rats (Barha et al., 2010). Acute estrone, however, either negatively affected or did not significantly influence contextual fear conditioning. Chronic high doses of either $17 \beta$-estradiol or estrone had no significant effects on Morris water maze learning in young adult female SD rats (McClure et al., 2013). A few studies have investigated the effects of Premarin, a hormone replacement therapy (HRT) that is comprised of 50\% estrone sulphate. Chronic daily injections of lower doses of Premarin impaired both spatial working and reference memory on the radial arm maze in young adult female rats (Barha and Galea, 2012). Furthermore, continuous delivery of Premarin via osmotic minipump dose-dependently regulated spatial reference and working memory, with the low dose impairing reference memory on the Morris water maze task, and the medium and high dose enhancing working memory on the water radial arm maze and the delayed match to sample task in young adult female rats (EnglerChiurazzi et al., 2011). When middle-aged ovariectomized female rats were treated cyclically (two days on, two days off) with Premarin performed better in the Morris water maze and the delay-match-to-sample task regardless of dose given (Acosta et al., 2009). Taken together, the studies described above show that estrogens produce a myriad of effects on hippocampusdependent task performance depending on factors such as estrogen, dose, type of task, and perhaps method of administration.

These various influences on performance may stem from the ability of estrogens to regulate learning strategy choice. Korol and colleagues (2004) showed that low endogenous levels of estrogens bias the rats toward striatal-dependent response strategies, while high endogenous levels of estrogens shift the preference toward hippocampus-dependent place strategies. Curiously spatial strategy use was associated with increased hippocampal cell proliferation in female rats but decreased hippocampal cell proliferation in male rats (Epp and Galea, 2009; Rummel et al., 2010). This illustrates that navigational strategies in the Morris water task is differentially related to changes in cell proliferation in the hippocampus in males 
and females. These studies suggest that high ovarian hormones may engage the hippocampus, promoting the use of hippocampus-dependent strategies and the production of new neurons.

Acute estradiol facilitates the induction of long-term potentiation (Smith and McMahon, 2006) and neuronal excitability via the inhibition of GABA (Rudick and Woolley, 2001).

Interestingly, both of these effects are dependent on the estradiol-induced increase in cholinergic transmissions in the basal forebrain (Daniel and Dohanich, 2001; Rudick et al., 2003).

Furthermore, estradiol-induced cholinergic activity positively correlated with spatial learning performance (Marriott and Korol, 2003), and the blockade of muscarinic receptors prevented estradiol's enhancement of spatial reference memory in the Morris water maze in female rats (Packard and Teather, 1997). Interestingly, both estradiol and acetylcholine can alter dopaminergic activity in the striatum (Zhou et al., 2002; Korol, 2004), although the dosedependent effects of acetylcholine are not well-characterized. Dopamine may also play a role as $\mathrm{D}_{2}$ receptor activity is reduced during proestrus, while the opposite is true during diestrus (Di Paolo et al., 1988). This is consistent with findings that low estradiol enhanced performance in a striatal-dependent plus maze task in a $\mathrm{D}_{2}$ receptor dependent manner (Daniel et al., 2006). Further strategy use with low estradiol was shifted from striatal to hippocampal-based strategies when a $D_{1}$ or $D_{2}$ antagonist was given concurrently (Quinlan et al., 2008). Taken together, these studies show that estradiol may dose-dependently regulate cognitive performance by altering learning strategies via the mediation of cholinergic and dopaminergic activity.

Estrogens differentially regulate neurogenesis and cognition depending on a number of factors such as estrogen type, dose and route of administration. Interestingly, adult-born neurons in the dentate gyrus also have a role in hippocampus-dependent learning and memory. Several studies have shown that learning can regulate neurogenesis depending on factors such as age of cells during learning (Dupret et al., 2007; Epp et al., 2007; Epp et al., 2011), task difficulty (Epp et al., 2010), sex (Dalla et al., 2009; Chow et al., 2013), and learning strategy (Epp and Galea, 2009; Rummel et al., 2010) in rats. On the other hand, downregulation of neurogenesis via irradiation or genetic knockdown impairs performance in contextual fear conditioning, pattern separation, spatial memory retrieval, and spatial discrimination in mice and rats (Snyder et al., 2005b; Saxe et al., 2006; Clelland et al., 2009). The role of estrogens in regulating adult neurogenesis and new neuron activation may be yet another mechanism by which estrogens influence learning and memory. However, very few studies so far have directly linked the cognitive effects of estrogens with its neurogenic effects.

Two recent studies showed that different estrogens not only differentially regulate adult neurogenesis, but also the activation of new neurons (measured by the immediate early gene (IEG) product zif268) in response to memory retrieval in female SD rats (Barha and Galea, 2012; McClure et al., 2013). McClure and colleagues (2013) found that 17 $\beta$-estradiol increased neurogenesis in the hippocampus and increased activation of these new neurons in response to spatial memory retrieval, while estrone decreased cell survival and had no significant effect on activation of these new neurons. Barha and Galea (2012) found that Premarin impaired spatial working and reference memory but increased neurogenesis in the hippocampus. They further 
found that the lower dose of Premarin reduced activation of 34-day old cells, while the higher dose of Premarin increased the activation of a younger population of adult-born cells (DCX) in response to spatial memory retrieval. Therefore, even when similar cognitive effects are produced, there are differences in the population of cells recruited for the memory trace depending on the type of estrogen and dose. It is also possible that the differences in neurogenic and cell activation effects between the estrogens would be more pronounced if a task more specific to the dentate gyrus, such as pattern separation (Leutgeb et al., 2007), was used. These data collectively show that it may not simply be the amount of neurogenesis or the number of new neurons activated in response to spatial memory but how these activated new neurons are related to performance.

One way to investigate this is to examine correlations between spatial performance and memory retrieval. Activation of new neurons in response to memory retrieval may be related to performance during learning, as Chow and colleagues (2013) showed that, in intact female rats, activation of 20-day old neurons were positively correlated with spatial learning performance. This relationship was not observed in males (Chow et al., 2013), and may be mediated by $17 \beta-$ estradiol , as McClure and colleagues (2013) showed that estradiol-treated rats had a positive correlation between spatial performance and activation of new neurons that was not seen in estrone-treated or vehicle-treated rats. Barha and Galea (2012) found that activation of 34-day old cells was associated with fewer working memory errors made during training in control, but not Premarin-treated, rats. Thus, the relationship between activation of new neurons and spatial performance differs with estrogen type with estradiol, but not estrone treatment, showing positive correlations between performance and activation of new neurons.

There are various possible mechanisms by which estrogens may regulate the survival and activation of new neurons during learning. IEG expression is indicative of neuronal activity such as that induced by long-term potentiation (LTP; (Worley et al., 1993), a cellular model of learning and memory (Lynch, 2004; Whitlock et al., 2006) and increases cell survival in male rats (Bruel-Jungerman et al., 2006). Smith and McMahon (2006) showed that estradiol regulates LTP induction via the NR2B subunit of the NMDA receptor. Interestingly, LTP can be induced in younger neurons which is blocked with the inhibition of NR2B (Snyder et al., 2001). BDNF also regulates adult neurogenesis, NR2B activity, and NR2B-dependent LTP (Crozier et al., 1999; Levine and Kolb, 2000; Scharfman et al., 2005) and estradiol regulates hippocampal BDNF mRNA levels in rats (Scharfman et al., 2005; Zhou et al., 2005). Therefore, estradiol may regulate the activation of adult-born neurons and their involvement in learning and memory via BDNF-mediation of the NR2B subunit. How this regulation differs depending on dose, estrogen type, route of administration, and various other factors, however, remains to be seen.

As mentioned earlier it is important to note that spatial learning, and likely other types of experience, can alter estrogens' effects on neurogenesis. For example, Premarin reduced neurogenesis in adult female rats but only when they also performed the radial arm maze task and not as cage controls Barha and Galea, 2012). Because, in that study, the spatially tested rats were also food-deprived it is possible that either/or food deprivation or spatial training in 
conjunction with Premarin caused the modulation in neurogenesis. In addition, repeated high levels of estradiol benzoate increase cell proliferation in cage controls but decrease cell proliferation when given in conjunction with cue-competition training in the Morris water maze in female SD rats (Barker and Galea, 2008; Rummel et al., 2010). These are similar findings to those investigating the effects of estradiol on dendritic spine density in female rats (Frick et al., 2004). These findings are important to acknowledge as they suggest that training experience influences the ability of estrogens to influence neuroplasticity in the hippocampus, much like reproductive experience (see earlier section).

\section{Estrogens and hippocampal neurogenesis}

Most work on estrogens and neurogenesis has been done with estradiol. Estradiol influences neurogenesis in the dentate gyrus by modulating cell proliferation and survival of young neurons but these effects are time-, dose-, age-, and sex-dependent (Table 1). In ovariectomized adult female rats, a single injection of a high dose of $17 \beta$-estradiol $(10 \mu \mathrm{g})$ rapidly increases cell proliferation after 30min and 2h, but not after 4h (Table 1; (Tanapat et al., 1999; Tanapat et al., 2005; Barha et al., 2009)). Interestingly, there is a sinusoidal relationship with estradiol's ability to increase cell proliferation in female rats with both a lower ( $0.3 \mu \mathrm{g}$; diestrous range) and higher dose (10 $\mu$ g; proestrous range) increasing cell proliferation but both medium and very high doses of estradiol do not significantly affect cell proliferation ( $1 \mu \mathrm{g}$ and $50 \mu \mathrm{g})$ (Tanapat et al., 2005; Barha et al., 2009). Predictably, estradiol benzoate, which is more slowly metabolized than $17 \beta$-estradiol, increases cell proliferation at a later time point (after $4 \mathrm{~h}$ ). Curiously $48 \mathrm{~h}$ after exposure of estradiol benzoate, cell proliferation is decreased in female rats and voles (Ormerod and Galea, 2001; Ormerod et al., 2003). Together, this research suggests that the effect of estradiol on cell proliferation in female rats and voles is time-dependent and transient: as there is a rapid increase, then a decrease in cell proliferation after estradiol exposure. The two-population model put forth by Nowakowski and Hayes (2008) presents a possible mechanism for this transient effect. According to this model, there are two populations of proliferative cells in the dentate gyrus: a progenitor steady state population and a replenishing stem cell population (Nowakowski and Hayes, 2008). Any modifications to one of the populations could affect the second population as a compensatory mechanism. Therefore it is possible that the time-dependent effects of estradiol may be due to the differential stimulation of these populations of proliferative cells. For example, after treatment with estradiol, the first population of progenitor cells would be stimulated to increase the rate of proliferation subsequently sending a signal to the second population of replenishing cells acting to reduce the rate of division in order to keep the population of proliferative cells constant. This dual population could counteract acute effects and keep neurogenesis levels in homeostasis in the dentate gyrus and could explain why longer times of exposure to acute estradiol does not significantly increase cell proliferation.

The effects of estradiol on the survival of adult born neurons have been less studied but vary depending on whether the DNA synthesis marker is injected prior to or after hormone 
treatment (see Figure 1). For instance, if BrdU is given one day prior to treatment estradiol benzoate decreases cell survival in ovariectomized female rats (Barker and Galea, 2008). Conversely, if BrdU is administered following the onset of $17 \beta$-estradiol treatment, estradiol increases cell survival in the hippocampus in female rats (McClure et al., 2013). When BrdU is administered prior to treatment, the effects of estradiol on cell survival are independent of the initial effects on cell proliferation, such as in the Barker and Galea (2008) study. However when, as in the McClure et al. study, BrdU is administered after hormone treatment, the effects of the number of BrdU-labelled cells surviving are also affected by the initial effects on cell

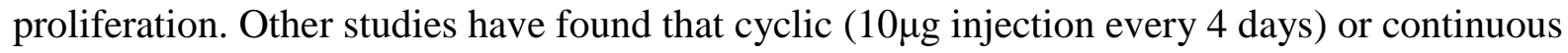
(via pellet) administration of $17 \beta$-estradiol for 8 days or 3 weeks did not significantly affect cell proliferation in female rats (Perez-Martin et al., 2003; Tanapat et al., 2005). Thus the effects of chronic estradiol on neurogenesis vary depending on the timing of BrdU injection relative to estradiol treatment and whether cell proliferation or cell survival is assessed (Table 1).

The time elapsed since ovariectomy also impacts cell proliferation in the hippocampus. Short term (6-7 days) ovariectomy decreases cell proliferation in rats relative to sham animals but not long-term ovariectomy (21 or 27 days) (Banasr et al., 2001; Tanapat et al., 2005; Green and Galea, 2008). Further estradiol given $28 \mathrm{~d}$ after ovariectomy failed to produce an increase in cell proliferation unlike estradiol given $7 \mathrm{~d}$ after ovariectomy (Tanapat et al., 2005). This result indicates that progenitor cells are no longer sensitive to estradiol after long-term deprivation. This is in line with the finding that long-term ovariectomy (5 months) renders the hippocampus resistant to estradiol treatment as estradiol fails to increase estrogen receptor expression to the same extent observed with immediate estradiol replacement is started immediately after ovariectomy (Bohacek and Daniel, 2009). Intriguingly, in middle-aged nulliparous female rats, neither ovariectomy nor exposure to different estrogens, including estradiol, affected cell proliferation in the hippocampus (Barha and Galea, 2011). This is in stark contrast to what is observed in young adult rats (e.g., (Tanapat et al., 2005; Barha et al., 2009)) and in middle-aged multiparous rats (Barha and Galea, 2011). These studies collectively suggest that the hippocampus loses its ability to respond to peripheral estradiol administration with age while parity appears to extend neural responsiveness to E2 (see above). It has been suggested that decreases in estrogen receptor content or reductions in steroid receptor coactivor-1 (SRC-1) during aging could impact the response of the hippocampus to estradiol (reviewed in (Zhang et al., 2011; Daniel, 2013). Additional research is needed to better understand the impact of longterm loss of gonadal function and aging on the brain (see above sections on Mechanisms of Estrogens in the Hippocampus and Aging, Reproductive Experience and Neurogenesis).

Recent research from our laboratory has shown that different types of estrogens can affect neurogenesis in the hippocampus. For example, acute administration of estrone ( 0.3 and $10 \mu \mathrm{g})$ and $17 \alpha$-estradiol $(1 \mu \mathrm{g})$, the optical isomer of $17 \beta$-estradiol, rapidly increase cell proliferation after 30min in young and middle-aged multiparous ovariectomized female rats (Barha et al., 2009; Barha and Galea, 2011). In contrast, chronic estrone administration (20 days) decreases neurogenesis in the hippocampus, while chronic estradiol increases neurogenesis, 
when both hormones are coupled with Morris water maze training (McClure et al., 2013). Other studies have also shown that spatial training can alter estrogen's effects on neurogenesis. For instance, 33 days of treatment with Premarin (a conjugated equine estrogen) has no significant effect on hippocampal neurogenesis in cage controls but Premarin increased neurogenesis in female rats tested in the radial arm maze (Barha and Galea, 2013). These studies suggest that the effect of estrogens on neurogenesis can be modified by experience such as spatial training (Barha and Galea, 2013; compare McClure et al., 2013 with Barker and Galea, 2008; compare Rummel et al., 2010 to Barker and Galea, 2008). The influence of training on the effects of estrogens on the hippocampus has been demonstrated before, as the ability of estradiol to promote dendritic spine density in the CA1 field of the hippocampus is attenuated when female rats performed a hippocampus-dependent task (Frick et al., 2004). Future studies are needed to determine the long-term effects of estrogens on hippocampal neurogenesis and the consequences these estrogen-mediated changes in neurogenesis may have on spatial learning and memory (see section above on Estrogens, Learning and Memory).

Finally, the ability of estrogens to promote neurogenesis in the hippocampus differs between the sexes (Tables 1 and 2). In adult males, 3-30 days of estradiol (estradiol benzoate or $17 \beta$-estradiol) exposure has no significant effect on neurogenesis (cell proliferation or cell survival) in castrated rats (Spritzer and Galea, 2007; Barker and Galea, 2008) or mice (Zhang et al., 2010). However, short-term estradiol increased cell survival in male meadow voles when administered during a very specific window during the cell maturation cycle, i.e., during the axon extension period (Ormerod et al., 2004). These studies indicate that estradiol plays a less prominent role in neurogenesis in the male hippocampus; however, the potential role of other estrogens, such as estrone and $17 \alpha$-estradiol, which are detectable in the male hippocampus (Toran-Allerand et al., 2005), has not yet been investigated.

\section{Mechanisms of estrogens in the hippocampus}

Estradiol exerts its physiological effects by binding to nuclear estrogen receptors (ER $\alpha$ and $\mathrm{ER} \beta$ ) that act as ligand-dependent transcription factors, binding to estrogen response elements in the promoters of target genes and regulating gene expression (Vasudevan and Pfaff, 2008). Recent evidence suggests that ERs can also be found in the plasma membrane (extranuclear ERs) and mediate fast non-genomic effects in the hippocampus (McEwen et al., 2012). ERs are found in progenitor cells in the subgranular zone of the dentate gyrus in rats (Perez-Martin et al., 2003; Mazzucco et al., 2006) and voles (Fowler et al., 2005), suggesting that the effects of estradiol on hippocampal neurogenesis might be mediated by ERs. In ovariectomized rats, administration of an ER $\alpha$ and ER $\beta$ agonist (PPT and DPN, respectively) increases cell proliferation (Mazzucco et al., 2006), while the effects of estradiol are partially blocked with an ER antagonist (ICI 182,780; (Nagy et al., 2006)). Interestingly, the ER agonists (alone or in combination) did not increase proliferation to the levels seen with estradiol (Mazzucco et al., 2006) suggesting that the modulation of neurogenesis by estradiol cannot be completely explained by the actions on ERs. In fact, other types of ERs have been recently 
identified (Toran-Allerand et al., 2002; Thomas et al., 2005). A G protein-coupled receptor (GPER, formally GPR30) has been recognized as an estrogen receptor localised in the plasma membrane and endoplasmic reticulum (reviewed in Prossnitz et al., 2008). GPER is expressed in the dentate gyrus, CA1, CA2, and CA3 regions of the hippocampus in male and female rats (Brailoiu et al., 2007). ICI 182,780 is a pure ER antagonist but can also bind to GPER as an agonist (Thomas et al., 2005). Administration of ICI 182,780 alone increases cell proliferation to similar levels as estradiol-treated female rats (Nagy et al., 2006) suggesting that estradiol might act through GPER to modulate some aspects of neurogenesis. The non-genomic actions of estradiol are rapid (seconds to minutes) and transient (between 1-4 h; (Vasudevan and Pfaff, 2008; Micevych and Dominguez, 2009)) which fits the timeline of the effect of $17 \beta$-estradiol on cell proliferation (after $30 \mathrm{~min}$ and $2 \mathrm{~h}$ but not after $4 \mathrm{~h}$ ) and suggests a fast non-genomic effect is at play. Finally, ER-X and Gq-mER are other recently identified estrogen receptors (ToranAllerand et al., 2002; Qiu et al., 2003). ER-X is detected during development in the neocortex (Micevych and Dominguez, 2009) and Gq-mER has been implicated in estrogen action related to reproduction and energy homeostasis in the hypothalamus (Micevych and Kelly, 2012). The roles of ER-X and Gq-mER in adult neurogenesis remain to be elucidated.

Estrogens are mainly produced in the gonads, however, it has been suggested that estrogen synthesis can also occur in other tissues such as the brain. Aromatase, the enzyme that converts testosterone to estradiol, is expressed in the hippocampus of rats, mice and monkeys (Fester et al., 2011). Although evidence exists for local production of steroids in embryonic or young tissue, levels of $17 \beta$-estradiol are very low or undetectable in the hippocampus of gonadectomized adult female mice (Toran-Allerand et al., 2005) and adult male and female rats (Barker and Galea, 2009). Testosterone levels were also very low or undetectable after long-term gonadectomy in male and female rats in the cerebral cortex and cerebellum (Caruso et al., 2010). Collectively these studies suggest that local estradiol synthesis is very limited in adult rodents in the hippocampus and may not play a significant role in mediating changes in neurogenesis. However, other studies suggest that neurosteroids may play a role in hippocampal neurogenesis (Okamoto et al., 2012).

The effects of estrogens on neurogenesis are also mediated by adrenal hormones, serotonin, and progesterone. For example, adrenalectomy eliminates the estradiol benzoate induced decrease in cell proliferation seen after $48 \mathrm{~h}$ of estradiol exposure in ovariectomized female rats (Ormerod et al., 2003). Estradiol stimulates adrenal activity by increasing corticosterone levels (Handa et al., 1994a) and adrenal steroids suppress neurogenesis in male and female rats (Brummelte and Galea, 2010), thus the decrease in cell proliferation $48 \mathrm{~h}$ after estradiol exposure is mediated by estradiol's stimulation of adrenal activity (Gould et al., 1992; Ormerod et al., 2003). In addition, Banasr et al. (2001) found that the estradiol-induced increase in cell proliferation in the dentate gyrus of female rats is mediated by serotonin. Inhibition of serotonin synthesis in ovariectomized rats blocks the ability of estradiol to increase cell proliferation (Banasr et al., 2001). These studies suggest a complex interplay between estrogens, adrenal hormones and serotonin in the regulation of hippocampal neurogenesis in female rats. 


\section{Progesterone and hippocampal neurogenesis}

There is increasing evidence that progesterone regulates both cell proliferation and survival in male and female rodents. In ovariectomized female rats, progesterone $(4 \mathrm{mg} / \mathrm{kg})$ increases cell proliferation in the subgranular zone after 1h (Liu et al., 2010; Bali et al., 2012), similar to the effect of estradiol. On the other hand, preliminary evidence suggests that chronic, 21-day, administration of progesterone (1 or $4 \mathrm{mg} / \mathrm{kg}$ ) or medroxyprogesterone acetate (MPA; 1 or $4 \mathrm{mg} / \mathrm{kg}$; synthetic progesterone that is sometimes used in hormone replacement therapy), does not affect neurogenesis in ovariectomized female rats (Chan, Chow, Hamson, and Galea, unpublished data). In male rats, progesterone treatment for 7 days increases cell proliferation but has no effects on survival (Barha et al., 2011). While in male mice, treatment with progesterone for 3 days increases cell survival after 7, 28, and 56 days. Specifically, progesterone increases the survival of very young newborn neurons (i.e., 0-7 day old neurons) as treatment with progesterone 7 days after BrdU administration did not increase the number of surviving cells after 28 days (Zhang et al., 2010).

Progesterone receptors are expressed in the hippocampus and a recent study localized progesterone nuclear receptors (PRs) and progesterone receptor membrane component-1 (Pgrmc1), a putative progesterone receptor, with progenitor cells and immature neurons in the subgranular zone (Bali et al., 2012). Treatment with a PR antagonist does not completely block the increase in cell survival in male mice co-treated with progesterone, while Src, MEK, or PI3K inhibitors are very effective at supressing the effect of progesterone (Zhang et al., 2010). These findings suggest that nuclear PRs are partially involved in regulating cell survival while an unknown receptor(s) activating Src-ERK and PI3K pathways is also involved (Zhang et al., 2010). From in vitro studies, it has been suggested that Pgrmc1 mediates the effects of progesterone on cell proliferation via a MAPK dependent pathway (Liu et al., 2009; Liu et al., 2010). Allopregnanolone, a progesterone metabolite, also increases cell proliferation in vitro (Wang et al., 2005; Liu et al., 2010) but its role in cell proliferation in male and females in vivo is unknown. In male mice, progesterone increases cell survival and this effect is still observed when mice are given progesterone and finasteride in combination (inhibiting the formation of allopregnanolone) (Zhang et al., 2010). This indicates that the effect of progesterone on cell survival is independent of some of its metabolites and that these metabolites do not regulate cell survival (Zhang et al., 2010). Further research in vivo is needed to determine the effects and mechanisms of action of progesterone in hippocampal neurogenesis.

Interestingly, progesterone interacts with estradiol to modulate neurogenesis.

Progesterone inhibits estradiol-induced cell proliferation in female rats. Rat received injections of $17 \beta$-estradiol or estradiol benzoate $(10 \mu \mathrm{g})$ for 2 days followed by an injection of progesterone and BrdU on day 3 (Tanapat et al., 2005; Bali et al., 2012). However, when estradiol and progesterone are injected at the same time into ovariectomized rats, the estradiol-induced increase in cell proliferation is not blocked but is lower than the levels seen with estradiol alone (Liu et al., 2010). While chronic MPA did not affect hippocampal neurogenesis in females, 
injection of MPA in conjunction with estradiol benzoate (10 $\mu \mathrm{g})$ for 21 days reduced cell survival in adult female rats (Chan, Chow, Hamson, and Galea,, unpublished data). Studies in vitro have shown that progesterone inhibits estradiol neuroprotection and BDNF expression in hippocampal rat slices (Aguirre and Baudry, 2009). Future research should address the level at which estradiol and progesterone interact to modulate neurogenesis.

\section{Androgens and Adult Hippocampal Neurogenesis}

Studies indicate that androgens upregulate adult hippocampal neurogenesis by increasing cell survival, with no significant effects on cell proliferation, in the dentate gyrus of male rodents (Ormerod and Galea, 2003; Spritzer and Galea, 2007). Omerod and Galea (2003) observed increased numbers of ${ }^{3} \mathrm{H}$-thymidine labelled cells suggesting increased rates of neurogenesis (via cell survival) in the dentate gyrus of reproductively active adult male meadow voles compared to non-reproductively active males. Male meadow voles are only reproductively active during the breeding season, a time when serum androgen levels are high, compared to the non-breeding season, when androgen levels are low. The rates of cell proliferation did not vary with breeding status, suggesting there is no relationship between androgen levels and cell proliferation in the dentate gyrus in male meadow voles.

Similarly, Spritzer and Galea (2007) did not observe an effect of long-term castration on cell proliferation in the hippocampus, but observed increased cell survival and neurogenesis in intact or castrated rats given testosterone compared to castrated male rats. Given that testosterone can be converted into either estradiol or a more potent androgen, dihydrotestosterone, it was necessary to determine which metabolite of testosterone was responsible for increasing neurogenesis in the dentate gryus of male rats. It was subsequently observed that castrated male rats given dihydrotestosterone displayed increased levels of neurogenesis in the dentate gyrus compared to castrated males treated with estradiol or vehicle, suggesting that androgens mediate the increase in new neuron survival in the dentate gyrus. In support of this, Hamson et al (2013) reported that the androgen-mediated increase in neurogenesis can be blocked by the androgen receptor antagonist, flutamide. In addition, hippocampal neurogenesis is significantly decreased in male rats harbouring a naturally occurring mutation in the gene encoding the androgen receptor (the so called testicular feminization mutation rat; TFM) rendering them insensitive to androgens (Hamson et al., 2013). TFMs chronically treated with pellets containing testosterone did not differ from TFMs treated with blank pellets, but both displayed significantly lower levels of adult hippocampaul neurogenesis compared to testosterone implanted wild type males. Finally, long-term castration or exposure to dihydrotestosterone did not affect the number of Ki67-expressing cells, suggesting that long-term androgen exposure or deprivation does not affect cell proliferation. These findings collectively suggest that androgens modulate survival of new neurons in the male dentate gyrus independent of cell proliferation.

Androgen receptors (ARs) have been identified in adult-derived neural progenitor cells isolated from the subventricular zone of adult female Wistar rats and from neural stem cells isolated from the striatum of embryonic male and female Wistar rats (Brännvall et al., 2005). In 
addition, nuclear AR expression was observed in the majority of dentate gyrus neurons in adult Wistar rats, although it is not clear if males or females were used for this part of the study (Brännvall et al., 2005). This latter point is an important distinction as there are sex differences in AR expression in the adult hippocampus (Xiao and Jordan, 2002). Curiously several reports indicate that there are no nuclear ARs in neurons of the male dentate gyrus in virtually all rat strains examined (Kerr et al., 1995; Xiao and Jordan, 2002; Tabori et al., 2005), except in Wistar rats (Brännvall et al., 2005). Using both light and electron microscopy, Tabori et al. (2005) showed ARs are expressed in axons and dendrites of the CA1 and CA3 regions, with the highest percentage of profiles found in the stratum lucidum of the CA3 region in the male rat. Presumptive AR immunoreactivity was not observed in any part of the granule cell layer of the dentate gyrus, but profiles were found in the infragranular layer and stratum pyramidale of the hilus; these regions are adjacent to the niche where new neurons are born in the adult hippocampus (i.e., the subgranular zone). We examined whether newborn neurons in the subgranular zone express ARs but failed to find a single new neuron that expressed this receptor (Hamson et al., 2013) in male Sprague-Dawley rats. As outlined below, the lack of AR expression in the dentate gyrus and immature neurons has implications for the role androgens play in the regulation of adult hippocampal neurogenesis. Given our observations, and others, of the absence of AR in immature (DCX-expressing) neurons of the dentate gyrus, this suggests that androgens mediate neuron survival via a mechanism that is initiated outside the dentate gyrus.

\section{Length of Androgen Treatment Affects Adult Hippocampal Neurogenesis}

The duration of androgen treatment is an important factor that determines whether androgens promote adult hippocampal neurogenesis in male rats as not all studies show that testosterone enhances neurogenesis. Carrier and Kabbaj (2012) reported no effect of testosterone implants on neurogenesis after 21 days of treatment. Similarly, Spritzer et al (2011) found no significant increase in cell survival in castrated male rats treated with testosterone for 15 days. In the studies that report that androgens promote new neuron survival, treatment lasted a minimum of 30 days (i.e., (Spritzer and Galea, 2007; Carrier and Kabbaj, 2012; Hamson et al., 2013). In addition, Brannvall et al (2005) found that 5 days of treatment with the anabolic androgenic steroid, 19-nortestosterone (nandrolone) in male rats decreased the number of new neurons in the dentate gyrus. Thus, taken together, it seems that a short duration of androgen treatment may decrease adult hippocampal neurogenesis whereas a longer duration of treatment, beyond 21 days, increases neurogenesis in the hippocampus. However, it is difficult to directly compare these studies as Brannvall et al (2005) used Wistar rats. As stated previously, this is the only strain of rat that displays AR in the dentate gyrus. Moreover, nortestosterone, the androgen used in this latter study has been suggested to recruit different steroid hormone regulators when bound to the AR than the androgens, testosterone or dihydrotestosterone, which could partially explain the discrepancies in results (MakLusky, Hajszan, Prange-Kiel, Leranth, 2005). Despite this, it is still evident that 30 days, but not 15 or 21 days, of androgen receptor activation is necessary to 
increase neurogenesis. Together, these studies suggest androgens mediate survival of neurons located in the dentate gyrus and, given the time frame involved, likely via a classical genomic mechanism.

\section{Dehydroepiandosterone (DHEA) and Neurogenesis}

Another androgen, DHEA, which is derived from the cortex of the adrenal glands and is present in the serum of rodents and the cerebral spinal fluid of humans, has also been implicated in hippocampal neurogenesis. Karishma and Herbert (2002) reported that DHEA increased neurogenesis by affecting both proliferation of cells and the survival of new neurons in the dentate gyrus (after 28 days) in rats. While the exact mechanism of DHEA in regulating neurogenesis is not known, these authors provided evidence that suppression of the corticosterone response was a possibility. DHEA, though, can act as an androgen receptor agonist. Lu et al, (2003) reported DHEA upregulated the expression of a reporter construct that contained an androgen response element suggesting direct activation of ARs by DHEA. Further, DHEA transactivated ARs, but the binding capacity of DHEA to AR was only 1/2000 compared to that of DHT suggesting that while DHEA does bind ARs it binds only weakly compared to more potent androgens (Chen et al., 2005). DHEA, like other androgens, regulates neurogenesis by affecting neuron survival, possibly by binding to the androgen receptor directly. However, unlike other androgens, DHEA can also increase rates of cell proliferation in the dentate gyrus, possibly through regulation of glucocorticoid receptor trafficking (Muller et al., 2004).

\section{How Do Androgens Increase Neuron Survival?}

Despite the necessity of androgen receptors in mediating new neuron survival in the adult male dentate gyrus, there is a "site of action" problem given that immature neurons do not express ARs. A similar problem exists in the development of motoneurons in the spinal nucleus of the bulbocavernosus (SNB). Motoneurons in the SNB normally die during the early postnatal period in both male and female rodents, but due to a surge in testosterone that only takes place in males (Weisz and Ward, 1980), the number of motoneurons lost is less in males compared to females. Various studies have shown that manipulations of gonadal steroids or AR during the early postnatal period can affect the number of SNB motoneurons in both males and females (Breedlove et al., 1982; Breedlove and Arnold, 1983; Nordeen et al., 1985). However, SNB motoneurons do not express ARs until after the critical developmental period has past but the target muscles (bulbocavernosus and levator ani) do express AR mRNA and protein during this period (Jordan et al., 1997; Smith et al., 2012). Thus androgens act on the bulbocavernosus and levator ani (Fishman and Breedlove, 1992) to initiate an as yet unidentified retrograde survival factor (Forger et al., 1993). In the brain, we suspect androgens are acting on the targets of new neurons in the dentate gyrus and regulating survival via a similar retrogradely transported survival mechanism that is secreted from the CA3 region. In support of this, granule neurons in the dentate gyrus contact specialized structures, termed thorny excrescences, located on CA3 pyramidal neurons (Hatanaka et al., 2009). The genesis of the thorny excrescences on CA3 
pyramidal neurons is also dependent upon androgens acting through the AR. Importantly, CA3 neurons also express ARs making them an attractive target to study the effects of androgens on neuron survival in the dentate gyrus (see Figure 2). Thus we believe it likely that ARs in the CA3 region contribute to the promotion of neurogenesis (via cell survival) in the dentate gyrus.

\section{Conclusions}

It is clear that gonadal and adrenal hormones play an important role in modulating hippocampus structure and function (see Table 2). Importantly, sex and experience (both reproductive and cognitive) also play an integral role in mediating the effects of steroid hormones on hippocampal neurogenesis, morphology, and cognition. It is vitally important to consider these additional factors in order to fully understand the nature of the steroid hormonehippocampus interaction. It is becoming evident that tailored treatment will be needed for certain neuropsychiatric and neurodegenerative disorders. Thus given our knowledge of that hormone exposure can alter the plasticity and structure of the brain, hormone status and experience may also be linked therapeutic treatments. As we continue to explore the fascinating world of hormonal modulation of neuroplasticity we need to embrace its complexity, as only in this way will we begin to completely understand the interaction between steroid hormones, sex, experience and neuroplasticity to fully appreciate their contribution to brain health.

Acknowledgements The authors gratefully acknowledge the technical and scientific influence of Stephanie Lieblich. This research has been supported over the years by Alzheimer's Society of Canada, Pacific Alzheimer Research Foundation, Coast Capital Depression Fund, NARSAD, NSERC and CIHR to LAMG. PDG is funded by a PDF award from NSERC. 


\section{References:}

Acosta JI, Mayer L, Talboom JS, Zay C, Scheldrup M, Castillo J, Demers LM, Enders CK, Bimonte-Nelson HA (2009) Premarin improves memory, prevents scopolamine-induced amnesia and increases number of basal forebrain choline acetyltransferase positive cells in middle-aged surgically menopausal rats. Hormones and Behavior 55:454-464.

Aguirre CC, Baudry M (2009) Progesterone reverses 17beta-estradiol-mediated neuroprotection and BDNF induction in cultured hippocampal slices. Eur J Neurosci 29:447-454.

Aizawa K, Ageyama N, Yokoyama C, Hisatsune T (2009) Age-Dependent Alteration in Hippocampal Neurogenesis Correlates with Learning Performance of Macaque Monkeys. Experimental Animals 58:403-407.

Alonso R, Griebel G, Pavone G, Stemmelin J, Le Fur G, Soubrie P (2004) Blockade of CRF(1) or V(1b) receptors reverses stress-induced suppression of neurogenesis in a mouse model of depression. Molecular psychiatry 9:278-286, 224.

Altman J (1962) Are new neurons formed in the brains of adult mammals? Science 135:1127-1128.

Anacker C, Zunszain PA, Cattaneo A, Carvalho LA, Garabedian MJ, Thuret S, Price J, Pariante CM (2011) Antidepressants increase human hippocampal neurogenesis by activating the glucocorticoid receptor. Molecular psychiatry 16:738-750.

Bali N, Arimoto JM, Iwata N, Lin SW, Zhao L, Brinton RD, Morgan TE, Finch CE (2012) Differential responses of progesterone receptor membrane component-1 (Pgrmc1) and the classical progesterone receptor (Pgr) to 17beta-estradiol and progesterone in hippocampal subregions that support synaptic remodeling and neurogenesis. Endocrinology 153:759-769.

Banasr M, Hery M, Brezun JM, Daszuta A (2001) Serotonin mediates oestrogen stimulation of cell proliferation in the adult dentate gyrus. Eur J Neurosci 14:1417-1424.

Bannerman DM, Rawlins JN, McHugh SB, Deacon RM, Yee BK, Bast T, Zhang WN, Pothuizen HH, Feldon J (2004) Regional dissociations within the hippocampus--memory and anxiety. Neuroscience and biobehavioral reviews 28:273-283.

Barha CK, Galea LAM (2010b) Influence of different estrogens on neuroplasticity and cognition in the hippocampus. Biochimica et Biophysica Acta 1800:1056-1067. .

Barha CK, Galea LAM (2011) Motherhood alters the cellular response to estrogens in the hippocampus later in life. Neurobiology of aging 32:2091-2095.

Barha CK, Galea LAM (2012) The hormone replacement therapy, Premarin, impairs hippocampusdependent spatial learning and memory and reduces activation of new granule neurons in response to memory in female rats. Neurobiology of Aging 34:986-1004.

Barha CK, Galea LA (2013) The hormone therapy, Premarin, impairs hippocampus-dependent spatial learning and memory and reduces activation of new granule neurons in response to memory in female rats. Neurobiol Aging 34:986-1004.

Barha CK, Lieblich SE, Galea LA (2009) Different forms of oestrogen rapidly upregulate cell proliferation in the dentate gyrus of adult female rats. J Neuroendocrinol 21:155-166.

Barha CK, Dalton GL, Galea LA (2010) Low doses of $17 \alpha$-estradiol and $17 \beta$-estradiol facilitate, whereas higher doses of estrone and $17 \alpha$ - and $17 \beta$-estradiol impair, contextual fear conditioning in adult female rats. Neuropsychopharmacology 35:547-559.

Barha CK, Ishrat T, Epp JR, Galea LA, Stein DG (2011) Progesterone treatment normalizes the levels of cell proliferation and cell death in the dentate gyrus of the hippocampus after traumatic brain injury. Exp Neurol 231:72-81.

Barker JM, Galea LA (2008) Repeated estradiol administration alters different aspects of neurogenesis and cell death in the hippocampus of female, but not male, rats. Neuroscience 152:888-902. 
Barker JM, Galea LA (2009) Sex and regional differences in estradiol content in the prefrontal cortex, amygdala and hippocampus of adult male and female rats. Gen Comp Endocrinol 164:77-84.

Barron AM, Pike CJ (2012) Sex hormones, aging, and Alzheimer's disease. Front Biosci (Elite Ed) 4:976997.

Ben Abdallah NM, Slomianka L, Vyssotski AL, Lipp HP (2010a) Early age-related changes in adult hippocampal neurogenesis in C57 mice. Neurobiol Aging 31:151-161.

Ben Abdallah NMB, Slomianka L, Vyssotski AL, Lipp H-P (2010b) Early age-related changes in adult hippocampal neurogenesis in C57 mice. Neurobiology of aging 31:151-161.

Bessa JM, Ferreira D, Melo I, Marques F, Cerqueira JJ, Palha JA, Almeida OF, Sousa N (2009) The moodimproving actions of antidepressants do not depend on neurogenesis but are associated with neuronal remodeling. Molecular psychiatry 14:764-773, 739.

Bimonte HA, Denenberg VH (1999) Estradiol facilitates performance as working memory load increases. Psychoneuroendocrinology 24:161-173.

Binder EB, Kunzel HE, Nickel T, Kern N, Pfennig A, Majer M, Uhr M, Ising M, Holsboer F (2009) HPA-axis regulation at in-patient admission is associated with antidepressant therapy outcome in male but not in female depressed patients. Psychoneuroendocrinology 34:99-109.

Bishop NA, Lu T, Yankner BA (2010) Neural mechanisms of ageing and cognitive decline. Nature 464:529535.

Bizon JL, Gallagher M (2003) Production of new cells in the rat dentate gyrus over the lifespan: relation to cognitive decline. European Journal of Neuroscience 18:215-219.

Bizon JL, Lee HJ, Gallagher M (2004) Neurogenesis in a rat model of age-related cognitive decline. Aging Cell 3:227-234.

Bohacek J, Daniel JM (2009) The ability of oestradiol administration to regulate protein levels of oestrogen receptor alpha in the hippocampus and prefrontal cortex of middle-aged rats is altered following long-term ovarian hormone deprivation. J Neuroendocrinol 21:640-647.

Boldrini M, Underwood MD, Hen R, Rosoklija GB, Dwork AJ, John Mann J, Arango V (2009) Antidepressants increase neural progenitor cells in the human hippocampus. Neuropsychopharmacology : official publication of the American College of Neuropsychopharmacology 34:2376-2389.

Boldrini M, Hen R, Underwood MD, Rosoklija GB, Dwork AJ, Mann JJ, Arango V (2012) Hippocampal Angiogenesis and Progenitor Cell Proliferation Are Increased with Antidepressant Use in Major Depression. Biological psychiatry.

Bondolfi L, Ermini F, Long JM, Ingram DK, Jucker M (2004) Impact of age and caloric restriction on neurogenesis in the dentate gyrus of C57BL/6 mice. Neurobiology of aging 25:333-340.

Brailoiu E, Dun SL, Brailoiu GC, Mizuo K, Sklar LA, Oprea TI, Prossnitz ER, Dun NJ (2007) Distribution and characterization of estrogen receptor $\mathrm{G}$ protein-coupled receptor 30 in the rat central nervous system. J Endocrinol 193:311-321.

Brännvall K, Bogdanovic N, Korhonen L, Lindholm D (2005) 19-Nortestosterone influences neural stem cell proliferation and neurogenesis in the rat brain. The European journal of neuroscience 21:871-878.

Breedlove SM, Arnold AP (1983) Hormonal control of a developing neuromuscular system. I. Complete Demasculinization of the male rat spinal nucleus of the bulbocavernosus using the antiandrogen flutamide. The Journal of neuroscience : the official journal of the Society for Neuroscience 3:417-423.

Breedlove SM, Jacobson CD, Gorski RA, Arnold AP (1982) Masculinization of the female rat spinal cord following a single neonatal injection of testosterone propionate but not estradiol benzoate. Brain research 237:173-181. 
Brett M, Baxendale S (2001) Motherhood and memory: a review. Psychoneuroendocrinology 26:339362.

Bridges RS (1975) LONG-TERM EFFECTS OF PREGNANCY AND PARTURITION UPON MATERNAL RESPONSIVENESS IN RAT. Physiology \& behavior 14:245-249.

Bridges RS, Byrnes EM (2006) Reproductive experience reduces circulating 17 beta-estradiol and prolactin levels during proestrus and alters estrogen sensitivity in female rats. Endocrinology 147:2575-2582.

Brown JP, Couillard-Despres S, Cooper-Kuhn CM, Winkler J, Aigner L, Kuhn HG (2003) Transient expression of doublecortin during adult neurogenesis. The Journal of comparative neurology 467:1-10.

Bruel-Jungerman E, Davis S, Rampon C, Laroche S (2006) Long-term potentiation enhances neurogenesis in the adult dentate gyrus. . Journal of Neuroscience 26:5888-5893.

Brummelte S, Galea LA (2010) Chronic high corticosterone reduces neurogenesis in the dentate gyrus of adult male and female rats. Neuroscience 168:680-690.

Buckwalter JG, Buckwalter DK, Bluestein BW, Stanczyk FZ (2001) Pregnancy and post partum: changes in cognition and mood. Progress in brain research 133:303-319.

Buddenberg TE, Komorowski M, Ruocco LA, Silva MA, Topic B (2009) Attenuating effects of testosterone on depressive-like behavior in the forced swim test in healthy male rats. Brain research bulletin 79:182-186.

Burgess A, Wainwright SR, Shihabuddin LS, Rutishauser U, Seki T, Aubert I (2008) Polysialic acid regulates the clustering, migration, and neuronal differentiation of progenitor cells in the adult hippocampus. Developmental neurobiology 68:1580-1590.

Burgess LH, Handa RJ (1992) Chronic estrogen-induced alterations in adrenocorticotropin and corticosterone secretion, and glucocorticoid receptor-mediated functions in female rats. Endocrinology 131:1261-1269.

Byrnes EM, Byrnes JJ, Bridges RS (2001) Increased sensitivity of dopamine systems following reproductive experience in rats. Pharmacology Biochemistry and Behavior 68:481-489.

Byrnes EM, Rigero BA, Bridges RS (2002) Dopamine antagonists during parturition disrupt maternal care and the retention of maternal behavior in rats. Pharmacology Biochemistry and Behavior 73:869-875.

Cameron HA, McKay RDG (1999) Restoring production of hippocampal neurons in old age. Nature neuroscience 2:894-897.

Cameron HA, McKay RD (2001) Adult neurogenesis produces a large pool of new granule cells in the dentate gyrus. The Journal of comparative neurology 435:406-417.

Carrier N, Kabbaj M (2012) Extracellular signal-regulated kinase 2 signaling in the hippocampal dentate gyrus mediates the antidepressant effects of testosterone. Biological psychiatry 71:642-651.

Caruso D, Pesaresi M, Maschi O, Giatti S, Garcia-Segura LM, Melcangi RC (2010) Effect of short-and longterm gonadectomy on neuroactive steroid levels in the central and peripheral nervous system of male and female rats. J Neuroendocrinol 22:1137-1147.

Chen F, Knecht K, Birzin E, Fisher J, Wilkinson H, Mojena M, Moreno CT, Schmidt A, Harada S, Freedman LP, Reszka AA (2005) Direct agonist/antagonist functions of dehydroepiandrosterone. Endocrinology 146:4568-4576.

Chow C, Epp JR, Lieblich SE, Barha CK, Galea LA (2013) Sex differences in neurogenesis and activation of new neurons in response to spatial learning and memory. Psychoneuroendocrinology 38:12361250.

Clelland CD, Choi M, Romberg C, Clemenson GD, Jr., Fragniere A, Tyers P, Jessberger S, Saksida LM, Barker RA, Gage FH, Bussey TJ (2009) A functional role for adult hippocampal neurogenesis in spatial pattern separation. Science 325:210-213. 
Cohen LS, Soares CN, Vitonis AF, Otto MW, Harlow BL (2006) Risk for new onset of depression during the menopausal transition: the Harvard study of moods and cycles. Archives of general psychiatry 63:385-390.

Crawley RA, Dennison K, Carter C (2003) Cognition in pregnancy and the first year post-partum. Psychol Psychother 76:69-84.

Crozier RA, Black IB, Plummer MR (1999) Blockade of NR2B-containing NMDA receptors prevents BDNF enhancement of glutamatergic transmission in hippocampal neurons. Learning and Memory 6:257-266.

Czeh B, Welt T, Fischer AK, Erhardt A, Schmitt W, Muller MB, Toschi N, Fuchs E, Keck ME (2002) Chronic psychosocial stress and concomitant repetitive transcranial magnetic stimulation: effects on stress hormone levels and adult hippocampal neurogenesis. Biological psychiatry 52:1057-1065.

Dalla C, Papachristos EB, Whetstone AS, Shors TJ (2009) Female rats learn trace memories better than male rats and consequently retain a greater proportion of new neurons in their hippocampi. Proceedings of the National Academy of Science 106:2927-2932.

Daniel JM (2013) Estrogens, estrogen receptors, and female cognitive aging: the impact of timing. Horm Behav 63:231-237.

Daniel JM, Dohanich G (2001) Acetylcholine mediates the estrogen-induced increase in NMDA receptor binding in CA1 of the hippocampus and the associated improvement in working memory. Journal of Neuroscience 21:6949-6956.

Daniel JM, Sulzer JK, Hulst JL (2006) Estrogen increases the sensitivity of ovariectomized rats to the disruptive effects produced by the antagonism of D2 but not D1 dopamine receptors during performance of a response learning task. Hormones and Behavior 49:38-44.

Daniel JM, Fader AJ, Spencer AL, Dohanich GP (1997) Estrogen enhances performance of female rats during acquisition of a radial arm maze. Hormones and Behavior 32:217-225.

Darnaudery M, Perez-Martin M, Del Favero F, Gomez-Roldan C, Garcia-Segura LM, Maccari S (2007) Early motherhood in rats is associated with a modification of hippocampal function. Psychoneuroendocrinology 32:803-812.

David DJ, Wang J, Samuels BA, Rainer Q, David I, Gardier AM, Hen R (2010) Implications of the functional integration of adult-born hippocampal neurons in anxiety-depression disorders. The Neuroscientist : a review journal bringing neurobiology, neurology and psychiatry 16:578-591.

David DJ, Samuels BA, Rainer Q, Wang JW, Marsteller D, Mendez I, Drew M, Craig DA, Guiard BP, Guilloux JP, Artymyshyn RP, Gardier AM, Gerald C, Antonijevic IA, Leonardo ED, Hen R (2009) Neurogenesis-dependent and -independent effects of fluoxetine in an animal model of anxiety/depression. Neuron 62:479-493.

Davis DM, Jacobson TK, Aliakbari S, Mizumori SJY (2005) Differential effects of estrogen on hippocampaland striatal-dependent learning. Neurobiology of Learning and Memory 84:132-137.

Dayer AG, Ford AA, Cleaver KM, Yassaee M, Cameron HA (2003) Short-term and long-term survival of new neurons in the rat dentate gyrus. The Journal of comparative neurology 460:563-572.

De Kloet ER, Reul JM (1987) Feedback action and tonic influence of corticosteroids on brain function: a concept arising from the heterogeneity of brain receptor systems. Psychoneuroendocrinology 12:83-105.

De Kloet ER, Vreugdenhil E, Oitzl MS, Joels M (1998) Brain corticosteroid receptor balance in health and disease. Endocrine reviews 19:269-301.

Dekker MC, Ferdinand RF, van Lang ND, Bongers IL, van der Ende J, Verhulst FC (2007) Developmental trajectories of depressive symptoms from early childhood to late adolescence: gender differences and adult outcome. Journal of child psychology and psychiatry, and allied disciplines 48:657-666. 
Deng W, Aimone JB, Gage FH (2010) New neurons and new memories: How does adult hippocampal neurogenesis affect learning and memory? Nature Reviews Neuroscience 11:339-350.

Di Paolo T, Falardeau P, Morissette M (1988) Striatal D-2 dopamine agonist binding sites fluctuate during the rat estrous cycle. Life Sci 43:665-672.

Dietrich T, Krings T, Neulen J, Willmes K, Erberich S, Thron A, Sturm W (2001) Effects of blood estrogen level on cortical activation patterns during cognitive activation as measured by functional MRI. Neuroimage 13:425-432.

Drapeau E, Mayo W, Aurousseau C, Le Moal M, Piazza PV, Abrous DN (2003) Spatial memory performances of aged rats in the water maze predict levels of hippocampal neurogenesis. Proceedings of the National Academy of Sciences of the United States of America 100:1438514390.

Driscoll I, Howard SR, Stone JC, Monfils MH, Tomanek B, Brooks WM, Sutherland RJ (2006) The aging hippocampus: A multi-level analysis in the rat. Neuroscience 139:1173-1185.

Dupret D, Fabre A, Dobrossy MD, Panatier A, Rodriguez JJ, Lamarque S, Lemaire V, Oliet SH, Piazza PV, Abrous DN (2007) Spatial learning depends on both the addition and removal of new hippocampal neurons. PLoS Biol 5:e214.

Eidelman Al, Hoffman NW, Kaitz M (1993) Cognitive deficits in women after childbirth. Obstetrics and Gynecology 81:764-767.

Engler-Chiurazzi E, Tsang C, Nonnenmacher S, Liang WS, Corneveaux JJ, Prokai L, Huentelman MJ, Bimonte-Nelson HA (2011) Tonic Premarin dose-dependently enhances memory, affects neurotrophin protein levels and alters gene expression in middle-aged rats. Neurobiology of Aging 32:680-697.

Epp JR, Galea LAM (2009) Hippocampus-dependent strategy choice predicts low levels of cell proliferation in the dentate gyrus. Neurobiology of Learning and Memory 91:437-446.

Epp JR, Spritzer MD, Galea LAM (2007) Hippocampus-dependent learning promotes survival of new neurons in the dentate gyrus at a specific time during cell maturation. Neuroscience 149:273285.

Epp JR, Barker JM, Galea LA (2009) Running wild: neurogenesis in the hippocampus across the lifespan in wild and laboratory-bred Norway rats. Hippocampus 19:1040-1049.

Epp JR, Haack AK, Galea LAM (2010) Task difficulty in the Morris water maze task influences the survival of new neurons in the dentate gyrus. Hippocampus 20:866-876.

Epp JR, Haack AK, Galea LAM (2011) Activation and survival of immature neurons in the dentate gyrus with spatial memory is dependent on time of exposure to spatial learning and age of cells at examination. Neurobiology of Learning and Memory 95:316-325.

Epp JR, Chow C, Galea LA (2013) Hippocampus-dependent learning influences hippocampal neurogenesis. Frontiers in neuroscience 7:57.

Epp JR, Beasley CL, L.A.M. G (in press) Increased hippocampal neurogenesis and p21 expression in depression: dependent on antidepressants, sex, age and antipsychotic exposure. Neuropsychopharmacology : official publication of the American College of Neuropsychopharmacology.

Eriksson PS, Perfilieva E, Bjork-Eriksson T, Alborn AM, Nordborg C, Peterson DA, Gage FH (1998) Neurogenesis in the adult human hippocampus. Nature medicine 4:1313-1317.

Espeland MA, Rapp SR, Shumaker SA, Brunner R, Manson JE, Sherwin BB, Hsia J, Margolis KL, Hogan PE, Wallace R, Dailey M, Freeman R, Hays J (2004) Conjugated equine estrogens and global cognitive function in postmenopausal women: Women's Health Initiative Memory Study. Jama 291:29592968.

Fanselow MS, Dong HW (2010) Are the dorsal and ventral hippocampus functionally distinct structures? Neuron 65:7-19. 
Fester L, Prange-Kiel J, Jarry H, Rune GM (2011) Estrogen synthesis in the hippocampus. Cell Tissue Res 345:285-294.

Fishman RB, Breedlove SM (1992) Local perineal implants of anti-androgen block masculinization of the spinal nucleus of the bulbocavernosus. Brain research Developmental brain research 70:283286.

Fleming A, Kuchera C, Lee A, Winocur G (1994) Olfactory-based social learning varies as a function of parity in female rats. Psychobiology 22:37-43.

Fleming AS, O'Day DH, Kraemer GW (1999) Neurobiology of mother-infant interactions: experience and central nervous system plasticity across development and generations. Neuroscience and biobehavioral reviews 23:673-685.

Forger NG, Roberts SL, Wong V, Breedlove SM (1993) Ciliary neurotrophic factor maintains motoneurons and their target muscles in developing rats. The Journal of neuroscience : the official journal of the Society for Neuroscience 13:4720-4726.

Foster TC (1999) Involvement of hippocampal synaptic plasticity in age-related memory decline. Brain research reviews 30:236-249.

Fowler CD, Johnson F, Wang Z (2005) Estrogen regulation of cell proliferation and distribution of estrogen receptor-alpha in the brains of adult female prairie and meadow voles. J Comp Neurol 489:166-179.

Frick KM (2012) Building a better hormone therapy? How understanding the rapid effects of sex steroid hormones could lead to new therapeutics for age-related memory decline. Behav Neurosci 126:29-53.

Frick KM, Fernandez SM, Bennett JC, Prange-Kiel J, MacLusky NJ, Leranth C (2004) Behavioral training interferes with the ability of gonadal hormones to increase CA1 spine synapse density in ovariectomized female rats. Eur J Neurosci 19:3026-3032.

Frodl T, Meisenzahl EM, Zetzsche T, Born C, Groll C, Jager M, Leinsinger G, Bottlender R, Hahn K, Moller $\mathrm{HJ}$ (2002) Hippocampal changes in patients with a first episode of major depression. The American journal of psychiatry 159:1112-1118.

Frye CA, Walf AA (2009) Depression-like behavior of aged male and female mice is ameliorated with administration of testosterone or its metabolites. Physiology \& behavior 97:266-269.

Gage FH (2000) Mammalian neural stem cells. Science 287:1433-1438.

Gage FH, Ray J, Fisher L (1995) Isolation, characterization, and use of stem cells from the CNS. Annual review of neuroscience 18:159-192.

Galea LA, McEwen BS (1999) Sex and seasonal differences in the rate of cell proliferation in the dentate gyrus of adult wild meadow voles. Neuroscience 89:955-964.

Galea LA, Kavaliers M, Ossenkopp KP, Hampson E (1995) Gonadal hormone levels and spatial learning performance in the Morris water maze in male and female meadow voles, Microtus pennsylvanicus. Hormones and Behavior 29:106-125.

Galea LA, McEwen BS, Tanapat P, Deak T, Spencer RL, Dhabhar FS (1997) Sex differences in dendritic atrophy of CA3 pyramidal neurons in response to chronic restraint stress. Neuroscience 81:689697.

Galea LA, Wide JK, Paine TA, Holmes MM, Ormerod BK, Floresco SB (2001) High levels of estradiol disrupt conditioned place preference learning, stimulus response learning and reference memory but have limited effects on working memory. Behav Brain Res 126:115-126.

Gatewood JD, Morgan MD, Eaton M, McNamara IM, Stevens LF, Macbeth AH, Meyer EAA, Lomas LM, Kozub FJ, Lambert KG, Kinsley CH (2005) Motherhood mitigates aging-related decrements in learning and memory an positively affects brain aging in the rat. Brain research bulletin 66:9198. 
Gibbs RB (1999) Estrogen replacement enhances acquisition of a spatial memory task and reduces deficits associated with hippocampal muscarinic receptor inhibition. Hormones and Behavior 36:222-233.

Gibbs RB, Gabor R (2003) Estrogen and cognition: applying preclinical findings to clinical perspectives. Journal of neuroscience research 74:637-643.

Gibbs RB, Johnson DA (2008) Sex specific effects of gonadectomy and hormone treatment on acquisition of a 12-arm radial maze task by Sprague-Dawley rat. Endocrinology 149:3176-3183.

Glynn LM (2010) Giving birth to a new brain: hormone exposures of pregnancy influence human memory. Psychoneuroendocrinology 35:1148-1155.

Glynn LM (2012) Increasing parity is associated with cumulative effects on memory. J Womens Health (Larchmt) 21:1038-1045.

Gold EB, Bromberger J, Crawford S, Samuels S, Greendale GA, Harlow SD, Skurnick J (2001) Factors associated with age at natural menopause in a multiethnic sample of midlife women. American Journal of Epidemiology 153:865-874.

Gould E, Cameron HA, Daniels DC, Woolley CS, McEwen BS (1992) Adrenal hormones suppress cell division in the adult rat dentate gyrus. The Journal of neuroscience : the official journal of the Society for Neuroscience 12:3642-3650.

Green AD, Galea LA (2008) Adult hippocampal cell proliferation is suppressed with estrogen withdrawal after a hormone-simulated pregnancy. Hormones and behavior 54:203-211.

Gutierrez-Lobos K, Scherer M, Anderer P, Katschnig H (2002) The influence of age on the female/male ratio of treated incidence rates in depression. $B M C$ psychiatry 2:3.

Hammarstrom A, Lehti A, Danielsson U, Bengs C, Johansson EE (2009) Gender-related explanatory models of depression: a critical evaluation of medical articles. Public health 123:689-693.

Hampson E (1990) Variations in sex-related cognitive abilities across the menstrual cycle. Brain Cognit 14:26-43.

Hamson DK, Wainwright SR, Taylor JR, Jones BA, Watson NV, Galea LA (2013) Androgens Increase Survival of Adult Born Neurons in the Dentate Gyrus by an Androgen Receptor Dependent Mechanism in Male Rats. Endocrinology.

Handa RJ, Burgess LH, Kerr JE, O'Keefe JA (1994a) Gonadal steroid hormone receptors and sex differences in the hypothalamo-pituitary-adrenal axis. Hormones and behavior 28:464-476.

Handa RJ, Nunley KM, Lorens SA, Louie JP, McGivern RF, Bollnow MR (1994b) Androgen regulation of adrenocorticotropin and corticosterone secretion in the male rat following novelty and foot shock stressors. Physiology \& behavior 55:117-124.

Harman SM, Brinton EA, Clarkson T, Heward CB, Hecht HS, Karas RH, Judelson DR, Naftolin F (2004) Is the WHI relevant to HRT started in the perimenopause? Endocrine 24:195-202.

Hastings NB, Gould E (1999) Rapid extension of axons into the CA3 region by adult-generated granule cells. The Journal of comparative neurology 413:146-154.

Hatanaka Y, Mukai H, Mitsuhashi K, Hojo Y, Murakami G, Komatsuzaki Y, Sato R, Kawato S (2009) Androgen rapidly increases dendritic thorns of CA3 neurons in male rat hippocampus. Biochemical and biophysical research communications 381:728-732.

Hattiangady B, Shetty AK (2008) Aging does not alter the number or phenotype of putative stem/progenitor cells in the neurogenic region of the hippocampus. Neurobiology of aging 29:129-147.

Hendrick V, Altshuler LL, Suri R (1998) Hormonal changes in the postpartum and implications for postpartum depression. Psychosomatics 39:93-101.

Hercher C, Turecki G, Mechawar N (2009) Through the looking glass: Examining neuroanatomical evidence for cellular alterations in major depression. J Psychiatr Res. 
Hogervorst E, Williams J, Budge M, Riedel W, Jolles J (2000) The nature of the effect of female gonadal hormone replacement therapy on cognitive function in post-menopausal women: a metaanalysis. Neuroscience 101:485-512.

Holmes MM, Wide JK, Galea LA (2002) Low levels of estradiol facilitate, whereas high levels of estradiol impair, working memory performance on the radial arm maze. Behav Neurosci 116:928-934.

Holsboer F (2000) The corticosteroid receptor hypothesis of depression. Neuropsychopharmacology : official publication of the American College of Neuropsychopharmacology 23:477-501.

Holsboer F (2001) Stress, hypercortisolism and corticosteroid receptors in depression: implications for therapy. Journal of affective disorders 62:77-91.

Huang GJ, Herbert J (2006) Stimulation of neurogenesis in the hippocampus of the adult rat by fluoxetine requires rhythmic change in corticosterone. Biological psychiatry 59:619-624.

Ising M, Horstmann S, Kloiber S, Lucae S, Binder EB, Kern N, Kunzel HE, Pfennig A, Uhr M, Holsboer F (2007) Combined dexamethasone/corticotropin releasing hormone test predicts treatment response in major depression - a potential biomarker? Biological psychiatry 62:47-54.

Jacobs BL, van Praag H, Gage FH (2000) Adult brain neurogenesis and psychiatry: a novel theory of depression. Molecular psychiatry 5:262-269.

Jaffe AB, Toranallerand CD, Greengard P, Gandy SE (1994) ESTROGEN REGULATES METABOLISM OF ALZHEIMER AMYLOID-BETA PRECURSOR PROTEIN. Journal of Biological Chemistry 269:1306513068.

Jordan CL, Padgett B, Hershey J, Prins G, Arnold A (1997) Ontogeny of androgen receptor immunoreactivity in lumbar motoneurons and in the sexually dimorphic levator ani muscle of male rats. The Journal of comparative neurology 379:88-98.

Kaplan MS, Hinds JW (1977) Neurogenesis in the adult rat: electron microscopic analysis of light radioautographs. Science 197:1092-1094.

Karishma KK, Herbert J (2002) Dehydroepiandrosterone (DHEA) stimulates neurogenesis in the hippocampus of the rat, promotes survival of newly formed neurons and prevents corticosterone-induced suppression. The European journal of neuroscience 16:445-453.

Keck ME (2006) Corticotropin-releasing factor, vasopressin and receptor systems in depression and anxiety. Amino acids 31:241-250.

Kempermann G, Kuhn HG, Gage FH (1998a) Experience-induced neurogenesis in the senescent dentate gyrus. The Journal of neuroscience : the official journal of the Society for Neuroscience 18:32063212.

Kempermann G, Kuhn HG, Gage FH (1998b) Experience-induced neurogenesis in the senescent dentate gyrus. Journal of Neuroscience 18:3206-3212.

Kempermann G, Gast D, Kronenberg G, Yamaguchi M, Gage FH (2003) Early determination and longterm persistence of adult-generated new neurons in the hippocampus of mice. Development 130:391-399.

Kerr JE, Allore RJ, Beck SG, Handa RJ (1995) Distribution and hormonal regulation of androgen receptor $(A R)$ and $A R$ messenger ribonucleic acid in the rat hippocampus. Endocrinology 136:3213-3221.

Kinsley CH, Madonia L, Gifford GW, Tureski K, Griffin GR, Lowry C, Williams J, Collins J, McLearie H, Lambert KG (1999) Motherhood improves learning and memory. Nature 402:137-138.

Kinsley CH, Trainer R, Stafisso-Sandoz G, Quadros P, Marcus LK, Hearon C, Meyer EAA, Hester N, Morgan M, Kozub FJ, Lambert KG (2006) Motherhood and the hormones of pregnancy modify concentrations of hippocampal neuronal dendritic spines. Hormones and behavior 49:131-142.

Kitay JI (1961) Sex differences in adrenal cortical secretion in the rat. Endocrinology 68:818-824.

Klaus F, Hauser T, Lindholm AK, Cameron HA, Slomianka L, Lipp HP, Amrein I (2012) Different regulation of adult hippocampal neurogenesis in Western house mice (Mus musculus domesticus) and C57BL/6 mice. Behav Brain Res 227:340-347. 
Kornstein SG, Schatzberg AF, Thase ME, Yonkers KA, McCullough JP, Keitner GI, Gelenberg AJ, Davis SM, Harrison WM, Keller MB (2000) Gender differences in treatment response to sertraline versus imipramine in chronic depression. The American journal of psychiatry 157:1445-1452.

Korol DL (2004) Role of estrogen in balancing contributions from multiple memory systems. Neurobiology of Learning and Memory 82:309-323.

Korol DL, Malin EL, Borden KA, Busby RA, Couper-Leo J (2004) Shifts in preferred learning strategy across the estrous cycle in female rats. Hormones and Behavior 45:330-338.

Kuhn HG, Dickinson-Anson H, Gage FH (1996) Neurogenesis in the dentate gyrus of the adult rat: agerelated decrease of neuronal progenitor proliferation. The Journal of neuroscience : the official journal of the Society for Neuroscience 16:2027-2033.

Lagace DC, Fischer SJ, Eisch AJ (2007) Gender and endogenous levels of estradiol do not influence adult hippocampal neurogenesis in mice. Hippocampus 17:175-180.

Lamberts SWJ, vandenBeld AW, vanderLely AJ (1997) The endocrinology of aging. Science 278:419-424.

Lavenex P, Steele MA, Jacobs LF (2000) The seasonal pattern of cell proliferation and neuron number in the dentate gyrus of wild adult eastern grey squirrels. Eur J Neurosci 12:643-648.

Lazarov O, Mattson MP, Peterson DA, Pimplikar SW, van Praag H (2010) When neurogenesis encounters aging and disease. Trends in neurosciences 33:569-579.

Le Mevel JC, Abitbol S, Beraud G, Maniey J (1979) Temporal changes in plasma adrenocorticotropin concentration after repeated neurotropic stress in male and female rats. Endocrinology 105:812-817.

Lemaire V, Koehl M, Le Moal M, Abrous DN (2000) Prenatal stress produces learning deficits associated with an inhibition of neurogenesis in the hippocampus. Proceedings of the National Academy of Sciences of the United States of America 97:11032-11037.

Lemaire V, Billard JM, Dutar P, George O, Piazza PV, Epelbaum J, Le Moal M, Mayo W (2006) Motherhood-induced memory improvement persists across lifespan in rats but is abolished by a gestational stress. European Journal of Neuroscience 23:3368-3374.

Leutgeb JK, Leutgeb S, Moser MB, Moser EI (2007) Pattern separation in the dentate gyrus and CA3 of the hippocampus. Science 315:961-966.

Levine ES, Kolb JE (2000) Brain-derived neurotrophic factor increases activity of NR2B-containing Nmethyl-

D-aspartate receptors in excised patches from hippocampal neurons. Journal of Neuroscience Research 62:357-362.

Lichtenwalner RJ, Forbes ME, Bennett SA, Lynch CD, Sonntag WE, Riddle DR (2001) Intracerebroventricular infusion of insulin-like growth factor-I ameliorates the age-related decline in hippocampal neurogenesis. Neuroscience 107:603-613.

Liu L, Wang J, Zhao L, Nilsen J, McClure K, Wong K, Brinton RD (2009) Progesterone increases rat neural progenitor cell cycle gene expression and proliferation via extracellularly regulated kinase and progesterone receptor membrane components 1 and 2. Endocrinology 150:3186-3196.

Liu L, Zhao L, She H, Chen S, Wang JM, Wong C, McClure K, Sitruk-Ware R, Brinton RD (2010) Clinically relevant progestins regulate neurogenic and neuroprotective responses in vitro and in vivo. Endocrinology 151:5782-5794.

Love G, Torrey N, McNamara I, Morgan M, Banks M, Hester NW, Glasper ER, DeVries AC, Kinsley CH, Lambert KG (2005) Maternal experience produces long-lasting behavioral modifications in the rat. Behavioral Neuroscience 119:1084-1096.

Lu S-F, Mo Q, Hu S, Garippa C, Simon NG (2003) Dehydroepiandrosterone upregulates neural androgen receptor level and transcriptional activity. Journal of neurobiology 57:163-171.

Lynch MA (2004) Long-term potentiation and memory. Physiol Rev 84:87-136. 
Ma X, Hamadeh MJ, Christie BR, Foster JA, Tarnopolsky MA (2012) Impact of treadmill running and sex on hippocampal neurogenesis in the mouse model of amyotrophic lateral sclerosis. PLoS One 7:e36048.

Macbeth AH, Luine VN (2010) Changes in anxiety and cognition due to reproductive experience: a review of data from rodent and human mothers. Neuroscience and biobehavioral reviews 34:452-467.

Macbeth AH, Scharfman HE, MacLusk NJ, Gautreaux C, Luine VN (2008) Effects of multiparity on recognition memory, monoaminergic neurotransmitters, and brain-derived neurotrophic factor (BDNF). Hormones and behavior 54:7-17.

Magarinos AM, McEwen BS (1995) Stress-induced atrophy of apical dendrites of hippocampal CA3C neurons: comparison of stressors. Neuroscience 69:83-88.

Malberg JE, Eisch AJ, Nestler EJ, Duman RS (2000) Chronic antidepressant treatment increases neurogenesis in adult rat hippocampus. The Journal of neuroscience : the official journal of the Society for Neuroscience 20:9104-9110.

Malykhin NV, Carter R, Seres P, Coupland NJ (2010) Structural changes in the hippocampus in major depressive disorder: contributions of disease and treatment. Journal of psychiatry \& neuroscience : JPN 35:337-343.

Marriott LK, Korol DL (2003) Short-term estrogen treatment in ovariectomized rats augments hippocampal acetylcholine release during place learning. Neurobiology of Learning and Memory 80:315-322.

Martinez-Canabal A, Akers KG, Josselyn SA, Frankland PW (2013) Age-dependent effects of hippocampal neurogenesis suppression on spatial learning. Hippocampus 23:66-74.

Matt DW, Sarver PL, Lu JKH (1987) RELATION OF PARITY AND ESTROUS CYCLICITY TO THE BIOLOGY OF PREGNANCY IN AGING FEMALE RATS. Biology of Reproduction 37:421-430.

Mazzucco CA, Lieblich SE, Bingham BI, Williamson MA, Viau V, Galea LA (2006) Both estrogen receptor alpha and estrogen receptor beta agonists enhance cell proliferation in the dentate gyrus of adult female rats. Neuroscience 141:1793-1800.

McClure RE, Barha CK, Galea LA (2013) 17beta-Estradiol, but not estrone, increases the survival and activation of new neurons in the hippocampus in response to spatial memory in adult female rats. Hormones and behavior 63:144-157.

McDonald HY, Wojtowicz JM (2005) Dynamics of neurogenesis in the dentate gyrus of adult rats. Neuroscience letters 385:70-75.

McEwen BS (1999) Stress and hippocampal plasticity. Annual review of neuroscience 22:105-122.

McEwen BS (2001) Plasticity of the hippocampus: adaptation to chronic stress and allostatic load. Annals of the New York Academy of Sciences 933:265-277.

McEwen BS, De Kloet ER, Rostene W (1986) Adrenal steroid receptors and actions in the nervous system. Physiological reviews 66:1121-1188.

McEwen BS, Akama KT, Spencer-Segal JL, Milner TA, Waters EM (2012) Estrogen effects on the brain: actions beyond the hypothalamus via novel mechanisms. Behav Neurosci 126:4-16.

McIntyre RS, Mancini D, Eisfeld BS, Soczynska JK, Grupp L, Konarski JZ, Kennedy SH (2006) Calculated bioavailable testosterone levels and depression in middle-aged men. Psychoneuroendocrinology 31:1029-1035.

McKay R (1997) Stem cells in the central nervous system. Science 276:66-71.

McKinnon MC, Yucel K, Nazarov A, MacQueen GM (2009) A meta-analysis examining clinical predictors of hippocampal volume in patients with major depressive disorder. J Psychiatry Neurosci 34:4154. 
Merrill DA, Karim R, Darraq M, Chiba AA, Tuszynski MH (2003) Hippocampal cell genesis does not correlate with spatial learning ability in aged rats. Journal of Comparative Neurology 459:201207.

Micevych P, Dominguez R (2009) Membrane estradiol signaling in the brain. Front Neuroendocrinol 30:315-327.

Micevych PE, Kelly MJ (2012) Membrane estrogen receptor regulation of hypothalamic function. Neuroendocrinology 96:103-110.

Miller IN, Cronin-Golomb A (2010) Gender differences in Parkinson's disease: clinical characteristics and cognition. Movement disorders : official journal of the Movement Disorder Society 25:26952703.

Miranda P, Williams CL, Einstein G (1999) Granule cells in aging rats are sexually dimorphic in their response to estradiol. Journal of Neuroscience 19:3316-3325.

Morgenstern NA, Lombardi G, Schinder AF (2008) Newborn granule cells in the ageing dentate gyrus. Journal of Physiology-London 586:3751-3757.

Muller C, Cluzeaud F, Pinon GM, Rafestin-Oblin M-E, Morfin R (2004) Dehydroepiandrosterone and its 7 hydroxylated metabolites do not interfere with the transactivation and cellular trafficking of the glucocorticoid receptor. The Journal of steroid biochemistry and molecular biology 92:469-476.

Muller HK, Wegener G, Popoli M, Elfving B (2011) Differential expression of synaptic proteins after chronic restraint stress in rat prefrontal cortex and hippocampus. Brain research 1385:26-37.

Nagy Al, Ormerod BK, Mazzucco CA, Galea LA (2006) Estradiol-induced enhancement in cell proliferation is mediated through estrogen receptors in the dentate gyrus of adult female rats. Drug Develop Res 66:142-149.

Nordeen EJ, Nordeen KW, Sengelaub DR, Arnold AP (1985) Androgens prevent normally occurring cell death in a sexually dimorphic spinal nucleus. Science (New York, NY) 229:671-673.

Nowakowski RS, Hayes NL (2008) Numerology of neurogenesis: characterizing the cell cycle of neurostem cells. In: Adult Neurogenesis (Gage FH, Kempermann G, Song H, eds), pp 7-23. Cold Spring Harbor: Cold Spring Harbor Laboratory Press.

Oatridge A, Holdcroft A, Saeed N, Hajnal JV, Puri BK, Fusi L, Bydder GM (2002) Change in brain size during and after pregnancy: study in healthy women and women with preeclampsia. AJNR Am J Neuroradiol 23:19-26.

Okamoto M, Hojo Y, Inoue K, Matsui T, Kawato S, McEwen BS, Soya H (2012) Mild exercise increases dihydrotestosterone in hippocampus providing evidence for androgenic mediation of neurogenesis. Proc Natl Acad Sci U S A 109:13100-13105.

Olariu A, Cleaver KM, Cameron HA (2007) Decreased neurogenesis in aged rats results from loss of granule cell precursors without lengthening of the cell cycle. Journal of Comparative Neurology 501:659-667.

Ormerod BK, Galea LA (2001) Reproductive status influences cell proliferation and cell survival in the dentate gyrus of adult female meadow voles: a possible regulatory role for estradiol. Neuroscience 102:369-379.

Ormerod BK, Galea LAM (2003) Reproductive status influences the survival of new cells in the dentate gyrus of adult male meadow voles. Neuroscience letters 346:25-28.

Ormerod BK, Lee TT, Galea LA (2003) Estradiol initially enhances but subsequently suppresses (via adrenal steroids) granule cell proliferation in the dentate gyrus of adult female rats. J Neurobiol 55:247-260.

Ormerod BK, Lee TT, Galea LA (2004) Estradiol enhances neurogenesis in the dentate gyri of adult male meadow voles by increasing the survival of young granule neurons. Neuroscience 128:645-654

Packard MG, Teather LA (1997) Posttraining estradiol injections enhance memory in ovariectomized rats: Cholinergic blockade and synergism. Neurobiology of Learning and Memory 68:172-188. 
Pariante CM, Lightman SL (2008) The HPA axis in major depression: classical theories and new developments. Trends in neurosciences 31:464-468.

Pariante CM, Thomas SA, Lovestone S, Makoff A, Kerwin RW (2004) Do antidepressants regulate how cortisol affects the brain? Psychoneuroendocrinology 29:423-447.

Paris JJ, Frye CA (2008) Estrous cycle, pregnancy, and parity enhance performance of rats in object recognition or object placement tasks. Reproduction 136:105-115.

Parker G, Parker K, Austin MP, Mitchell P, Brotchie H (2003) Gender differences in response to differing antidepressant drug classes: two negative studies. Psychological medicine 33:1473-1477.

Pawluski JL, Galea LAM (2005) Hippocampal morphology is differentially affected by reproductive experience in the mother. Journal of Neurobiology 66:71-81.

Pawluski JL, Galea LAM (2007) Reproductive experience alters hippocampal neurogenesis during the postpartum period in the dam. Neuroscience 149:53-67.

Pawluski JL, Walker SK, Galea LA (2006a) Reproductive experience differentially affects spatial reference and working memory performance in the mother. Hormones and behavior 49:143-149.

Pawluski JL, Vanderbyl BL, Ragan K, Galea LAM (2006b) First reproductive experience persistently affects spatial reference and working memory in the mother and these effects are not due to pregnancy or 'mothering' alone. Behavioral Brain Research 175:157-165.

Pawluski JL, Brummelte S, Barha CK, Crozier TM, Galea LA (2009) Effects of steroid hormones on neurogenesis in the hippocampus of the adult female rodent during the estrous cycle, pregnancy, lactation and aging. Frontiers in neuroendocrinology 30:343-357.

Perez-Martin M, Azcoitia I, Trejo JL, Sierra A, Garcia-Segura LM (2003) An antagonist of estrogen receptors blocks the induction of adult neurogenesis by insulin-like growth factor-I in the dentate gyrus of adult female rat. Eur J Neurosci 18:923-930.

Pfaff DW, Rapin I, Goldman S (2011) Male predominance in autism: neuroendocrine influences on arousal and social anxiety. Autism research : official journal of the International Society for Autism Research 4:163-176.

Pope HG, Jr., Cohane GH, Kanayama G, Siegel AJ, Hudson JI (2003) Testosterone gel supplementation for men with refractory depression: a randomized, placebo-controlled trial. The American journal of psychiatry 160:105-111.

Pope HG, Jr., Amiaz R, Brennan BP, Orr G, Weiser M, Kelly JF, Kanayama G, Siegel A, Hudson JI, Seidman SN (2010) Parallel-group placebo-controlled trial of testosterone gel in men with major depressive disorder displaying an incomplete response to standard antidepressant treatment. Journal of clinical psychopharmacology 30:126-134.

Prickaerts J, Koopmans G, Blokland A, Scheepens A (2004) Learning and adult neurogenesis: survival with or without proliferation? Neurobiology of learning and memory 81:1-11.

Prossnitz ER, Oprea TI, Sklar LA, Arterburn JB (2008) The ins and outs of GPR30: a transmembrane estrogen receptor. J Steroid Biochem Mol Biol 109:350-353.

Qiu J, Bosch MA, Tobias SC, Grandy DK, Scanlan TS, Ronnekleiv OK, Kelly MJ (2003) Rapid signaling of estrogen in hypothalamic neurons involves a novel G-protein-coupled estrogen receptor that activates protein kinase $C$. The Journal of neuroscience : the official journal of the Society for Neuroscience 23:9529-9540.

Quinlan MG, Hussain D, Brake WG (2008) Use of cognitive strategies in rats: the role of estradiol and its interaction with dopamine. Hormones and behavior 53:185-191.

Rannevik G, Jeppsson S, Johnell O, Bjerre B, Laurell-Borulf Y, Svanberg L (1995) A longitudinal study of the perimenopausal transition: altered profiles of steroid and pituitary hormones, SHBG and bone mineral density. Maturitas 21:103-113. 
Rao MS, Hattiangady B, Abdel-Rahman A, Stanley DP, Shetty AK (2005) Newly born cells in the ageing dentate gyrus display normal migration, survival and neuronal fate choice but endure retarded early maturation. European Journal of Neuroscience 21:464-476.

Rapp SR, Espeland MA, Shumaker SA, Henderson VW, Brunner RL, Manson JE, Gass ML, Stefanick ML, Lane DS, Hays J, Johnson KC, Coker LH, Dailey M, Bowen D (2003) Effect of estrogen plus progestin on global cognitive function in postmenopausal women: the Women's Health Initiative Memory Study: a randomized controlled trial. Jama 289:2663-2672.

Rasgon NL, Altshuler LL, Fairbanks LA, Dunkin JJ, Davtyan C, Elman S, Rapkin AJ (2002) Estrogen replacement therapy in the treatment of major depressive disorder in perimenopausal women. The Journal of clinical psychiatry 63 Suppl 7:45-48.

Reynolds BA, Weiss S (1992) Generation of neurons and astrocytes from isolated cells of the adult mammalian central nervous system. Science 255:1707-1710.

Rocha BA, Fleischer R, Schaeffer JM, Rohrer SP, Hickey GJ (2005) 17 Beta-estradiol-induced antidepressant-like effect in the forced swim test is absent in estrogen receptor-beta knockout (BERKO) mice. Psychopharmacology 179:637-643.

Rosenblatt JS (1988) Psychoneuroendocrine aspects of maternal behavior. Psychoneuroendocrinology 13:3-212.

Rudick CN, Woolley CS (2001) Estrogen regulates functional inhibition of hippocampal CA1 pyramidal cells in the adult female rat. Journal of Neuroscience 21:6532-6543.

Rudick CN, Gibbs RB, Woolley CS (2003) A role for the basal forebrain cholinergic system in estrogeninduced disinhibition of hippocampal pyramidal cells. Journal of Neuroscience 23:4479-4490.

Rummel J, Epp JR, Galea LAM (2010) Estradiol does not influence strategy choice but place strategy choice is associated with increased cell proliferation in the hippocampus of female rats. Hormones and Behavior 58:582-590.

Ryan J, Scali J, Carriere I, Ritchie K, Ancelin ML (2008) Hormonal treatment, mild cognitive impairment and Alzheimer's disease. Int Psychogeriatr 20:47-56.

Sanai N, Nguyen T, Ihrie RA, Mirzadeh Z, Tsai HH, Wong M, Gupta N, Berger MS, Huang E, GarciaVerdugo JM, Rowitch DH, Alvarez-Buylla A (2011) Corridors of migrating neurons in the human brain and their decline during infancy. Nature 478:382-386.

Santarelli L, Saxe M, Gross C, Surget A, Battaglia F, Dulawa S, Weisstaub N, Lee J, Duman R, Arancio O, Belzung C, Hen R (2003) Requirement of hippocampal neurogenesis for the behavioral effects of antidepressants. Science 301:805-809.

Sapolsky RM (1986) Glucocorticoid toxicity in the hippocampus: reversal by supplementation with brain fuels. J Neurosci 6:2240-2244.

Sapolsky RM, Krey LC, McEwen BS (1984) GLUCOCORTICOID-SENSITIVE HIPPOCAMPAL-NEURONS ARE INVOLVED IN TERMINATING THE ADRENOCORTICAL STRESS RESPONSE. Proceedings of the National Academy of Sciences of the United States of America-Biological Sciences 81:6174-6177.

Sapolsky RM, Packan DR, Vale WW (1988) Glucocorticoid toxicity in the hippocampus: in vitro demonstration. Brain Res 453:367-371.

Saxe MD, Battaglia F, Wang JW, Malleret G, David DJ, Monckton JE, Garcia AD, Sofroniew MV, Kandel ER, Santarelli L, Hen R, Drew MR (2006) Ablation of hippocampal neurogenesis impairs contextual fear conditioning and synaptic plasticity in the dentate gyrus. Proceedings of the National Academy of Science 103.

Scanlan VF, Byrnes EM, Bridges RS (2006) Reproductive experience and activation of maternal memory. Behavioral Neuroscience 120:676-686.

Scharfman H, Goodman J, Macleod A, Phani S, Antonelli C, Croll S (2005) Increased neurogenesis and the ectopic granule cells after intrahippocampal BDNF infusion in adult rats. Exp Neurol 192:348356. 
Scharfman HE, MacLusky NJ (2006) Estrogen and brain-derived neurotrophic factor (BDNF) in hippocampus: Complexity of steroid hormone-growth factor interactions in the adult CNS. Frontiers in neuroendocrinology 27:415-435.

Schule C (2007) Neuroendocrinological mechanisms of actions of antidepressant drugs. Journal of neuroendocrinology 19:213-226.

Schule C, Baghai T, Zwanzger P, Rupprecht R (2001) Attenuation of HPA axis hyperactivity and simultaneous clinical deterioration in a depressed patient treated with mirtazapine. The world journal of biological psychiatry : the official journal of the World Federation of Societies of Biological Psychiatry 2:103-105.

Schule C, Baghai TC, Eser D, Zwanzger P, Jordan M, Buechs R, Rupprecht R (2006) Time course of hypothalamic-pituitary-adrenocortical axis activity during treatment with reboxetine and mirtazapine in depressed patients. Psychopharmacology 186:601-611.

Schule C, Baghai T, Zwanzger P, Ella R, Eser D, Padberg F, Moller HJ, Rupprecht R (2003) Attenuation of hypothalamic-pituitary-adrenocortical hyperactivity in depressed patients by mirtazapine. Psychopharmacology 166:271-275.

Seaberg RM, van der Kooy D (2003) Stem and progenitor cells: the premature desertion of rigorous definitions. Trends in neurosciences 26:125-131.

Seidman SN, Rabkin JG (1998) Testosterone replacement therapy for hypogonadal men with SSRIrefractory depression. Journal of affective disorders 48:157-161.

Seidman SN, Spatz E, Rizzo C, Roose SP (2001) Testosterone replacement therapy for hypogonadal men with major depressive disorder: a randomized, placebo-controlled clinical trial. The Journal of clinical psychiatry 62:406-412.

Seki T, Arai Y (1995) Age-related production of new granule cells in the adult dentate gyrus. Neuroreport 6:2479-2482.

Sell SL, Craft RM, Seitz PK, Stutz SJ, Cunningham KA, Thomas ML (2008) Estradiol-sertraline synergy in ovariectomized rats. Psychoneuroendocrinology 33:1051-1060.

Sheline YI, Gado MH, Kraemer HC (2003) Untreated depression and hippocampal volume loss. The American journal of psychiatry 160:1516-1518.

Sheline YI, Wang PW, Gado MH, Csernansky JG, Vannier MW (1996) Hippocampal atrophy in recurrent major depression. Proceedings of the National Academy of Sciences of the United States of America 93:3908-3913.

Sherwin BB (2005) Estrogen and memory in women: how can we reconcile the findings? Horm Behav 47:371-375.

Sherwin BB (2006) Estrogen and cognitive aging in women. Neuroscience 138:1021-1026.

Sherwin BB, Henry JF (2008) Brain aging modulates the neuroprotective effects of estrogen on selective aspects of cognition in women: a critical review. Frontiers in Neuroendocrinology 29:88-113.

Shores MM, Moceri VM, Sloan KL, Matsumoto AM, Kivlahan DR (2005) Low testosterone levels predict incident depressive illness in older men: effects of age and medical morbidity. The Journal of clinical psychiatry 66:7-14.

Shores MM, Kivlahan DR, Sadak TI, Li EJ, Matsumoto AM (2009) A randomized, double-blind, placebocontrolled study of testosterone treatment in hypogonadal older men with subthreshold depression (dysthymia or minor depression). The Journal of clinical psychiatry 70:1009-1016.

Shores MM, Sloan KL, Matsumoto AM, Moceri VM, Felker B, Kivlahan DR (2004) Increased incidence of diagnosed depressive illness in hypogonadal older men. Archives of general psychiatry 61:162167.

Shors TJ, Miesegaes G, Beylin A, Zhao M, Rydel T, Gould E (2001) Neurogenesis in the adult is involved in the formation of trace memories. Nature 410:372-376. 
Shumaker SA, Legault C, Rapp SR, Thal L, Wallace RB, Ockene JK, Hendrix SL, Jones BN, 3rd, Assaf AR, Jackson RD, Kotchen JM, Wassertheil-Smoller S, Wactawski-Wende J (2003) Estrogen plus progestin and the incidence of dementia and mild cognitive impairment in postmenopausal women: the Women's Health Initiative Memory Study: a randomized controlled trial. Jama 289:2651-2662.

Smith CC, McMahon LL (2006) Estradiol-induced increase in the magnitude of long-term potentiation is prevented by blocking NR2B-containing receptors. Journal of Neuroscience 26:8517-8522.

Smith MR, Hamson DK, Poort JE, Jordan CL, Breedlove SM (2012) Ontogeny of androgen receptor expression in spinal nucleus of the bulbocavernosus motoneurons and their target muscles in male mice. Neuroscience letters 513:119-123.

Snyder JS, Kee N, Wojtowicz JM (2001) Effects of adult neurogenesis on synaptic plasticity in

the rat dentate gyrus. J Neurophysiol 85:2423-2431.

Snyder JS, Hong NS, McDonald RJ, Wojtowicz JM (2005a) A role for adult neurogenesis in spatial longterm memory. Neuroscience 130:843-852.

Snyder JS, Hong NS, McDonald RJ, Wojtowicz JM (2005b) A role for adult neurogenesis in spatial longterm memory. Neuroscience 130:843-852.

Snyder JS, Soumier A, Brewer M, Pickel J, Cameron HA (2011) Adult hippocampal neurogenesis buffers stress responses and depressive behaviour. Nature 476:458-461.

Snyder JS, Choe JS, Clifford MA, Jeurling SI, Hurley P, Brown A, Kamhi JF, Cameron HA (2009) Adult-born hippocampal neurons are more numerous, faster maturing, and more involved in behavior in rats than in mice. The Journal of neuroscience : the official journal of the Society for Neuroscience 29:14484-14495.

Soares CN, Almeida OP, Joffe H, Cohen LS (2001) Efficacy of estradiol for the treatment of depressive disorders in perimenopausal women: a double-blind, randomized, placebo-controlled trial. Archives of general psychiatry 58:529-534.

Soares CN, Poitras JR, Prouty J, Alexander AB, Shifren JL, Cohen LS (2003) Efficacy of citalopram as a monotherapy or as an adjunctive treatment to estrogen therapy for perimenopausal and postmenopausal women with depression and vasomotor symptoms. The Journal of clinical psychiatry 64:473-479.

Spalding KL, Bergmann O, Alkass K, Bernard S, Salehpour M, Huttner HB, Bostrom E, Westerlund I, Vial C, Buchholz BA, Possnert G, Mash DC, Druid H, Frisen J (2013) Dynamics of hippocampal neurogenesis in adult humans. Cell 153:1219-1227.

Speisman RB, Kumar A, Rani A, Pastoriza JM, Severance JE, Foster TC, Ormerod BK (2013) Environmental enrichment restores neurogenesis and rapid acquisition in aged rats. Neurobiology of aging 34:263-274.

Spritzer MD, Galea LAM (2007) Testosterone and dihydrotestosterone, but not estradiol, enhance survival of new hippocampal neurons in adult male rats. Developmental neurobiology 67:13211333.

Spritzer MD, Ibler E, Inglis W, Curtis MG (2011) Testosterone and social isolation influence adult neurogenesis in the dentate gyrus of male rats. Neuroscience 195:180-190.

Stockmeier CA, Mahajan GJ, Konick LC, Overholser JC, Jurjus GJ, Meltzer HY, Uylings HB, Friedman L, Rajkowska G (2004) Cellular changes in the postmortem hippocampus in major depression. Biol Psychiatry 56:640-650.

Stone GE, Miller OL, Prescott DM (1965) H-Thymidine Derivative Pools in Relation to Macronuclear DNA Synthesis in Tetrahymena Pyriformis. The Journal of cell biology 25:171-177. 
Surget A, Saxe M, Leman S, Ibarguen-Vargas Y, Chalon S, Griebel G, Hen R, Belzung C (2008) Drugdependent requirement of hippocampal neurogenesis in a model of depression and of antidepressant reversal. Biological psychiatry 64:293-301.

Surget A, Tanti A, Leonardo ED, Laugeray A, Rainer Q, Touma C, Palme R, Griebel G, Ibarguen-Vargas $Y$, Hen R, Belzung C (2011) Antidepressants recruit new neurons to improve stress response regulation. Molecular psychiatry 16:1177-1188.

Tabori NE, Stewart LS, Znamensky V, Romeo RD, Alves SE, McEwen BS, Milner TA (2005) Ultrastructural evidence that androgen receptors are located at extranuclear sites in the rat hippocampal formation. Neuroscience 130:151-163.

Talboom JS, Williams BJ, Baxley ER, West SG, Bimonte-Nelson HA (2008) Higher levels of estradiol replacement correlate with better spatial memory in surgically menopausal young and middleaged rats. Neurobiology of learning and memory 90:155-163.

Tanapat P, Hastings NB, Gould E (2005) Ovarian steroids influence cell proliferation in the dentate gyrus of the adult female rat in a dose- and time-dependent manner. J Comp Neurol 481:252-265.

Tanapat P, Hastings NB, Reeves AJ, Gould E (1999) Estrogen stimulates a transient increase in the number of new neurons in the dentate gyrus of the adult female rat. J Neurosci 19:5792-5801.

Tapia-Arancibia L, Aliaga E, Silhol M, Arancibia S (2008) New insights into brain BDNF function in normal aging and Alzheimer disease. Brain research reviews 59:201-220.

Taupin P (2007) BrdU immunohistochemistry for studying adult neurogenesis: paradigms, pitfalls, limitations, and validation. Brain research reviews 53:198-214.

Thase ME, Entsuah R, Cantillon M, Kornstein SG (2005) Relative antidepressant efficacy of venlafaxine and SSRIs: sex-age interactions. J Womens Health (Larchmt) 14:609-616.

Thomas P, Pang Y, Filardo EJ, Dong J (2005) Identity of an estrogen membrane receptor coupled to a G protein in human breast cancer cells. Endocrinology 146:624-632.

Tomizawa K, Iga N, Lu YF, Moriwaki A, Matsushita M, Li ST, Miyamoto O, Itano T, Matsui H (2003) Oxytocin improves long-lasting spatial memory during motherhood through MAP kinase cascade. Nature neuroscience 6:384-390.

Toni N, Laplagne DA, Zhao C, Lombardi G, Ribak CE, Gage FH, Schinder AF (2008) Neurons born in the adult dentate gyrus form functional synapses with target cells. Nature neuroscience 11:901-907.

Toran-Allerand CD, Tinnikov AA, Singh RJ, Nethrapalli IS (2005) 17alpha-estradiol: a brain-active estrogen? Endocrinology 146:3843-3850.

Toran-Allerand CD, Guan X, MacLusky NJ, Horvath TL, Diano S, Singh M, Connolly ES, Jr., Nethrapalli IS, Tinnikov AA (2002) ER-X: a novel, plasma membrane-associated, putative estrogen receptor that is regulated during development and after ischemic brain injury. J Neurosci 22:8391-8401.

Tulchinsky D, Hobel CJ, Yeager E, Marshall JR (1972) Plasma estrone, estradiol, estriol, progesterone, and 17-hydroxyprogesterone in human pregnancy. I. Normal pregnancy. American journal of obstetrics and gynecology 112:1095-1100.

Turner PR, O'Connor K, Tate WP, Abraham WC (2003) Roles of amyloid precursor protein and its fragments in regulating neural activity, plasticity and memory. Progress in neurobiology 70:1-32.

van der Kooy D, Weiss S (2000) Why stem cells? Science 287:1439-1441.

van Praag H, Kempermann G, Gage FH (1999) Running increases cell proliferation and neurogenesis in the adult mouse dentate gyrus. Nature neuroscience 2:266-270.

van Praag H, Shubert T, Zhao CM, Gage FH (2005) Exercise enhances learning and hippocampal neurogenesis in aged mice. Journal of Neuroscience 25:8680-8685.

Vanston CM, Watson NV (2005) Selective and persistent effect of foetal sex on cognition in pregnant women. Neuroreport 16:779-782.

Vasudevan N, Pfaff DW (2008) Non-genomic actions of estrogens and their interaction with genomic actions in the brain. Front Neuroendocrinol 29:238-257. 
Veras AB, Nardi AE (2010) The complex relationship between hypogonadism and major depression in a young male. Progress in neuro-psychopharmacology \& biological psychiatry 34:421-422.

Vest RS, Pike CJ (2013) Gender, sex steroid hormones, and Alzheimer's disease. Hormones and behavior 63:301-307.

Viau V (2002) Functional cross-talk between the hypothalamic-pituitary-gonadal and -adrenal axes. Journal of neuroendocrinology 14:506-513.

Viau V, Meaney MJ (1991) Variations in the hypothalamic-pituitary-adrenal response to stress during the estrous cycle in the rat. Endocrinology 129:2503-2511.

Viau V, Meaney MJ (1996) The inhibitory effect of testosterone on hypothalamic-pituitary-adrenal responses to stress is mediated by the medial preoptic area. The Journal of neuroscience : the official journal of the Society for Neuroscience 16:1866-1876.

Videbech P, Ravnkilde B (2004) Hippocampal volume and depression: a meta-analysis of MRI studies. The American journal of psychiatry 161:1957-1966.

Vollmayr B, Mahlstedt MM, Henn FA (2007) Neurogenesis and depression: what animal models tell us about the link. European archives of psychiatry and clinical neuroscience 257:300-303.

von Bohlen und Halbach O (2011) Immunohistological markers for proliferative events, gliogenesis, and neurogenesis within the adult hippocampus. Cell and tissue research 345:1-19.

Wainwright SR, Galea LA (2013) The Neural Plasticity Theory of Depression: Assessing the roles of Adult Neurogenesis and PSA-NCAM within the Hippocampus. Neural Plasticity.

Wainwright SR, Lieblich SE, Galea LA (2011) Hypogonadism predisposes males to the development of behavioural and neuroplastic depressive phenotypes. Psychoneuroendocrinology 36:1327-1341.

Wang JM, Johnston PB, Ball BG, Brinton RD (2005) The neurosteroid allopregnanolone promotes proliferation of rodent and human neural progenitor cells and regulates cell-cycle gene and protein expression. J Neurosci 25:4706-4718.

Warren SG, Juraska JM (1997) Spatial and nonspatial learning across the rat estrous cycle. Behavioral Neuroscience 111:259-266.

Watanabe Y, Gould E, McEwen BS (1992) Stress induces atrophy of apical dendrites of hippocampal CA3 pyramidal neurons. Brain research 588:341-345.

Weisz J, Ward IL (1980) Plasma testosterone and progesterone titers of pregnant rats, their male and female fetuses, and neonatal offspring. Endocrinology 106:306-316.

Westenbroek C, Den Boer JA, Veenhuis M, Ter Horst GJ (2004) Chronic stress and social housing differentially affect neurogenesis in male and female rats. Brain research bulletin 64:303-308.

Whitlock JR, Heynen AJ, Shuler MG, Bear MF (2006) Learning induces long-term potentiation in the hippocampus. Science 313.

Wilkinson CW, Peskind ER, Raskind MA (1997) Decreased hypothalamic-pituitary-adrenal axis sensitivity to cortisol feedback inhibition in human aging. Neuroendocrinology 65:79-90.

Willner P (2005) Chronic mild stress (CMS) revisited: consistency and behavioural-neurobiological concordance in the effects of CMS. Neuropsychobiology 52:90-110.

Winocur G, Wojtowicz JM, Sekeres M, Snyder JS, Wang S (2006) Inhibition of neurogenesis interferes with hippocampus-dependent memory function. Hippocampus 16:296-304.

Workman JL, Barha CK, Galea LA (2012) Endocrine substrates of cognitive and affective changes during pregnancy and postpartum. Behav Neurosci 126:54-72.

Worley PF, Bhat RV, Baraban JM, Erickson CA, McNaughton BL, Barnes CA (1993) Thresholds for synaptic activation of transcription factors in hippocampus: correlation with long-term enhancement. Journal of Neuroscience 13:4776-4786.

Xiao L, Jordan CL (2002) Sex differences, laterality, and hormonal regulation of androgen receptor immunoreactivity in rat hippocampus. Hormones and behavior 42:327-336. 
Zarrouf FA, Artz S, Griffith J, Sirbu C, Kommor M (2009) Testosterone and depression: systematic review and meta-analysis. Journal of psychiatric practice 15:289-305.

Zhang D, Guo Q, Bian C, Zhang J, Lin S, Su B (2011) Alterations of steroid receptor coactivator-1 (SRC-1) immunoreactivities in specific brain regions of young and middle-aged female Sprague-Dawley rats. Brain research 1382:88-97.

Zhang Z, Yang R, Zhou R, Li L, Sokabe M, Chen L (2010) Progesterone promotes the survival of newborn neurons in the dentate gyrus of adult male mice. Hippocampus 20:402-412.

Zhou F, Wilson C, Dani J (2002) Cholinergic interneurons characteristics and nicotinic properties in the striatum. Journal of Neurobiology 53:590-605.

Zhou J, Zhang H, Cohen RS, Pandey SC (2005) Effects of estrogen treatment on expression of brainderived neurotrophic factor and CAMP response element-binding protein expression and phosphorylation in rat amygdaloid and hippocampal structures. Neuroendocrinology 81:294310.

Zobel AW, Yassouridis A, Frieboes RM, Holsboer F (1999) Prediction of medium-term outcome by cortisol response to the combined dexamethasone-CRH test in patients with remitted depression. The American journal of psychiatry 156:949-951.

Zobel AW, Nickel T, Sonntag A, Uhr M, Holsboer F, Ising M (2001) Cortisol response in the combined dexamethasone/CRH test as predictor of relapse in patients with remitted depression. a prospective study. Journal of psychiatric research 35:83-94. 


\section{Figure Captions}

Figure $1 \mathrm{~A}$. Rough timeline of the maturation of new neurons in the dentate gyrus of adult rats. It is important to keep in mind that the timeline of maturation of new neurons in adult mice differs when reviewing the literature of hormone effects on neurogenesis (Snyder et al., 2009). Neural progenitor cells that divide form two daughter cells within $24 \mathrm{~h}$ (Cameron and McKay, 2001) while new neurons extend axons into the Schaeffer collaterals 4-10 days after production (Hastings and Gould, 1999). New neurons begin to express mature neuronal protein as early as two weeks after production (Brown et al., 2003) B The time of exposure of BrdU, or any DNA synthesis marker, in combination with hormones (or any treatment) can profoundly affect the results and depends on the question of interest. In panel B1 if rodents are perfused within 24 hours of BrdU injection, BrdU-labelled cells will measure cell proliferation (more specifically if perfused in less than $24 \mathrm{~h}$, labelled cells will be progenitor cells that are dividing at time of BrdU injection, while at $24 \mathrm{~h}$ labelled cells will be newly divided daughter cells). Note that duration of hormone exposure prior to BrdU can significantly impact the number of dividing cells. For example if BrdU is given 30 min after estradiol cell proliferation is increased while if BrdU is given 4 $\mathrm{h}$ after estradiol exposure there is no significant change in cell proliferation (Barha et al., 2009). Panel B2 and B3, BrdU-labelled cells after 29-30 days will express mature neuronal markers and this paradigm will examine the effects of hormones on the survival of BrdU-labelled cells. However, BrdU given $24 \mathrm{~h}$ prior to hormone treatment will be examining the effects of hormone exposure on the survival of new cells independent of any initial cell proliferation effects of the hormone (B2), while BrdU given $24 \mathrm{~h}$ after hormone exposure will be examining the effects of hormone exposure on cell survival dependent in part on any hormone effects on initial cell proliferation (B3). NPC - neural precursor cells; BrdU bromodeoxyuridine.,

Figure 2. Androgens increase survival of newborn neurons $(\mathrm{N})$ in the dentate gyrus by binding to androgen receptors in the CA3 region of the adult hippocampus. Activation of the androgen receptor by androgens, such as dihydrotestosterone (DHT), initiates the expression of a survival factor that is retrogradely sent to the newborn neurons in the dentate gyrus. Proliferating cells $(\mathrm{P})$ in the subgranular zone (SGZ), however, are not affected by androgen treatment. 
A
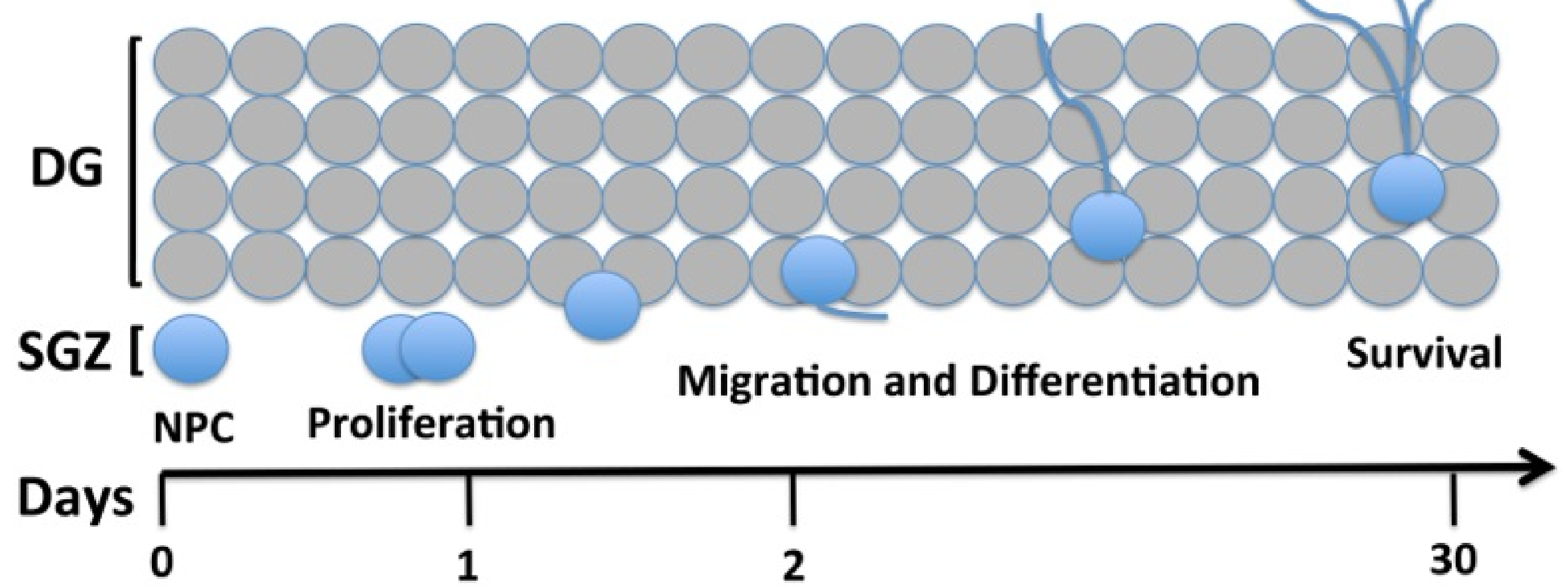

1. BrdU + Hormone

Days

0

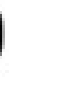

2. Brdu

Days

0

0

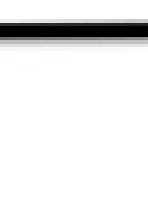

(x)

Hormone

$\nabla$

(1)

perfuse

Migration and Differentiation

Survival 


\section{CA1}

\section{Retrograde Survival Factor}

\section{Dentate Gyrus}

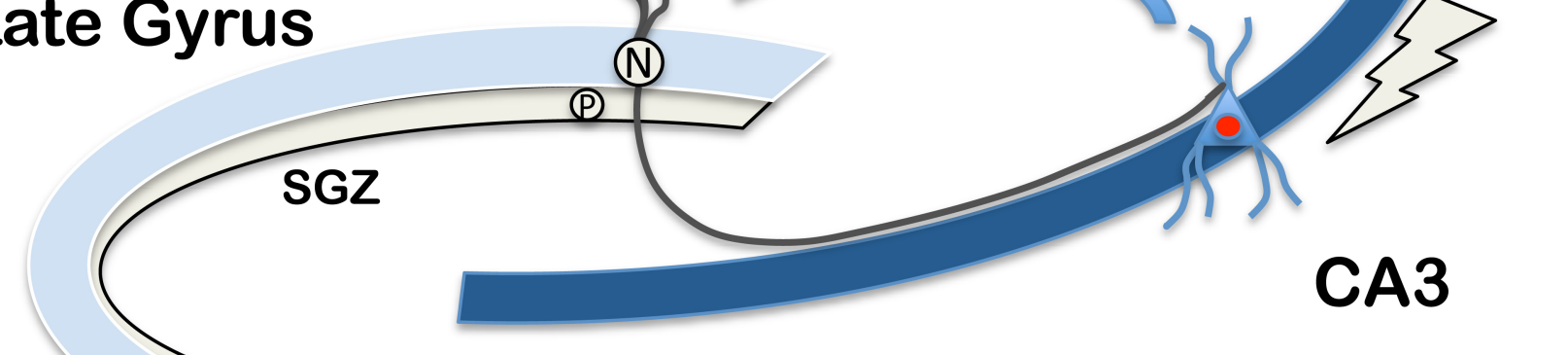

